\title{
Analysis of Asymmetrical Deformation of Surface and Oblique Pipeline Caused by Shield Tunneling along Curved Section
}

\author{
Huangshi Deng ${ }^{1,2} \mathbb{D}$, Helin Fu ${ }^{2}$, Yue Shi ${ }^{1,2}$, Zhen Huang ${ }^{3, *}$ and Qibing Huang ${ }^{1,2}$ \\ 1 School of Civil Engineering, Central South University, Changsha 410075, China; tunneldhs@csu.edu.cn (H.D.); \\ yueshi@csu.edu.cn (Y.S.); tunnelFKT@csu.edu.cn (Q.H.) \\ 2 National Engineering Laboratory for Construction Technology of High-Speed Railway, \\ Central South University, Changsha 410075, China; fu.h.1@csu.edu.cn \\ 3 Key Laboratory of Disaster Prevention and Structural Safety, College of Civil Engineering and Architecture, \\ Guangxi University, Nanning 530004, China \\ * Correspondence: hzcslg@163.com
}

Citation: Deng, H.; Fu, H.; Shi, Y.; Huang, Z; Huang, Q. Analysis of Asymmetrical Deformation of Surface and Oblique Pipeline Caused by Shield Tunneling along Curved Section. Symmetry 2021, 13, 2396. https://doi.org/10.3390/sym13122396

Academic Editors: Igor V. Andrianov and Raffaele Barretta

Received: 8 November 2021

Accepted: 10 December 2021

Published: 12 December 2021

Publisher's Note: MDPI stays neutral with regard to jurisdictional claims in published maps and institutional affiliations.

Copyright: () 2021 by the authors. Licensee MDPI, Basel, Switzerland. This article is an open access article distributed under the terms and conditions of the Creative Commons Attribution (CC BY) license (https:// creativecommons.org/licenses/by/ $4.0 /)$.

\begin{abstract}
The deformation of existing pipelines caused by the tunneling of a shield machine along curved sections has not been sufficiently researched, and a corresponding theoretical prediction formula is lacking. This paper derives a prediction formula for the deformation of an existing pipeline caused by shield machine tunneling along a curved section. Further, a finite difference model (FDM) corresponding to an actual project is built. Finally, the deformation of the surface and existing pipelines caused by shield machine tunneling along the curved section is analyzed. The research results show that the results of theoretical prediction, FDM calculation, and field monitoring data are consistent. In addition, the deformation of the surface and the existing pipeline are asymmetrically distributed when the shield machine tunnels along the curve section instead of symmetrically distributed (for straight line segment). When the pipeline is perpendicular to the tunnel axis, the maximum deformation position of the existing pipeline deviates from the tunnel axis by about 0.5 times the tunnel radius. In addition, as the angle $\beta$ between the pipeline axis and the tunnel axis increases, the maximum deformation position of the pipeline gradually approaches the tunnel axis.
\end{abstract}

Keywords: shield tunnel; asymmetrical deformation; pipeline deformation analysis; oblique; FDM

\section{Introduction}

The urban underground space is considerably limited, and the distribution of energy pipelines and transportation pipelines in the underground space is intricate. These pipelines are usually buried at a shallow depth with low stiffness and easily deform or even crack due to surrounding disturbances. Foundation pit excavation, temporary stacking, and tunnel excavation projects, which are widespread in cities, can cause additional stress and deformation of the surrounding soil [1], threatening the safety of surrounding structures, especially underground pipelines [2].

The shield method is the primary construction method in urban subway engineering and energy corridor engineering. The disturbance to the surrounding environment caused by shield machine tunneling has also been an extensively researched topic in recent years. Ma et al. [3] analyze the influence of shallow-buried double-line parallel rectangular pipejacking construction on ground settlement deformation by 3D numerical simulation. Fang et al. [4] introduced a case in which closely spaced twin tunnels were excavated beneath other closely spaced existing twin tunnels in Beijing, and they monitored the settlement of the existing tunnels and the ground surface associated with the construction of new tunnels. Zhang et al. [5] proposed an analytical solution to investigate the response of an existing tunnel induced by the excavation of a new tunnel underneath. Miliziano and de Lillis [6] investigated the effects induced by the mechanized excavation of Rome Metro 
line $C$ in the area of an old masonry building by using 3D soil tunnel-structure interaction numerical analyses. Cheng et al. [7] introduced a case history where two shield tunnels pass between two excavation pits belonging to the east square of the existing Zhengzhou East High-Speed Rail (HSR) station. Lin et al. [8] investigated the deformation behaviors of existing tunnels with new twin tunnel construction undercrossing obliquely based on field monitoring data and numerical simulation methods. Simultaneously, many studies have used numerical simulation and theoretical analysis to analyze the deformation of existing pipelines caused by shield machine tunneling. Yu et al. [9] provided an expression of the Winkler subgrade modulus and then used the superposition principle and the Fourier integral to analyze tunneling effects on existing pipelines. Cheng et al. [10] investigated the mechanical behavior of a buried pipe under the stratum by finite element models. Ni and Mangalathu [11] combined the Gaussian distribution curve of settlement and the beam-onspring model, derived the empirical formula for the deformation of the existing pipeline caused by the tunneling of the shield machine, and verified the formula by conducting a centrifugal test and numerical simulation. Huang et al. [1] proposed an improved Winkler modulus to analyze the response of jointed pipelines due to tunneling, which was verified against field measurement data and centrifuge tests. Zhang and Zhang [12] conducted a continuous elastic analysis in the finite difference form to simulate the responses of both continuous and jointed pipelines subjected to tunnel-induced soil movement in multilayered soils. Hou et al. [13] introduced a disastrous ground failure of the kind that occurred during the Beijing Subway Line 10 construction. In this case, several ground failures occurred due to pipeline damage induced by tunnel construction. Zhang et al. [14] compared the effect of soil stratification on the pipeline behavior subject to tunnel-induced soil movements by using the Galerkin solution and a layered transfer matrix solution. The above studies usually only considered shield machine tunneling along a straight section, and few studies focused on shield machine tunneling along a curved section. At the same time, most of the previous studies did not consider the situation in which the existing pipeline and the tunneling axis are obliquely intersected. However, in actual engineering, subway lines are highly complicated, and shield machines often tunnel along curved sections. For example, the intercity railway from the Zhuhai urban area to the airport [15], Changsha subway line 1 and line 6 [16], Jinan subway line 4 [17], and Anhui subway line 4 [18] have many curved sections. Meanwhile, the oblique intersection of an existing pipeline and the tunneling axis of the shield machine is more common than the orthogonal or parallel intersection. Therefore, clarifying the deformation characteristics of an existing pipeline caused by shield machine tunneling along a curved section is important.

Theoretical analysis requires less time and effort compared with numerical simulation and indoor test methods, and it can provide design and construction personnel with predictive data in the early stage of the project [19]. In this study, the Wanjiali power tunnel project in Changsha City, China, was analyzed in three parts. In the first part, the calculation formula of the surrounding ground settlement caused by shield machine tunneling along the curved section was deduced based on the Mindlin solution and the mirror-image convergence method. Then, the theoretical prediction formula of the existing pipeline deformation caused by shield machine tunneling along the curved section was further deduced by considering the coupling effect of the soil and the pipeline. In the second part, a numerical calculation model corresponding to the Wanjiali power tunnel project was constructed. Then, the theoretical formula prediction results, finite difference model (FDM) calculation results, and field monitoring data were compared to verify the rationality of the theoretical calculation formula and FDM. Finally, in the third part, the effects of different curvature radii $R_{0}$, pipeline buried depths $h$, pipeline materials, and tunnel excavation radii $R$ on existing pipeline deformation were investigated based on the theoretical prediction formula. 


\section{Project Overview}

The Wanjiali power tunnel in Changsha City, China, is being constructed by the shield method. This tunnel is being laid along Wanjiali Road, which is the main road in a densely populated area of the city and has residential areas, schools, and hotels on both sides. Moreover, the distribution of underground pipelines along the road is exceptionally complicated. The total length of the tunnel is approximately $6.8 \mathrm{~km}$, of which $6.1 \mathrm{~km}$ is being constructed by the shield method. The section between the Liuyang River (DK2 + 819) and Fuyuan Road (DK3 + 560) is the most challenging construction interval of this project, as shown in Figure 1. In this section, the shield machine tunnels have multiple curved sections so that the direction remains consistent with Wanjiali Road. The minimum radius of the curvature of the curved section is only $150 \mathrm{~m}$; such a small radius of the curved section is extremely rare in shield machine construction worldwide. Shield machine tunneling along a curved section involves more complicated construction factors than tunneling along a straight section. Therefore, it is necessary to clarify the deformation of the existing pipeline caused by shield machine tunneling along the curved section.
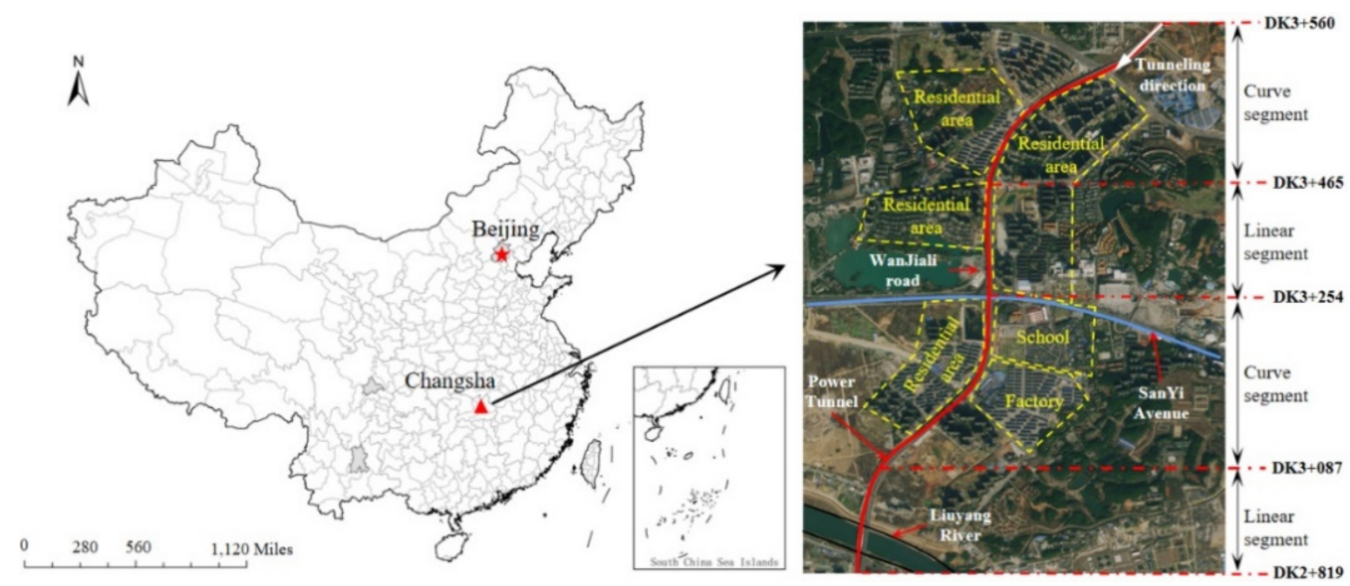

Figure 1. Project location.

The area of tunnel construction is located on the alluvial terraces of the Liuyang River. The overburden layer above the tunnel consists of miscellaneous fill, silty clay stratum, silt stratum, and sandy cobble stratum. The groundwater depth is 4-9 m below the ground surface, with an average depth of approximately $3.8 \mathrm{~m}$. The buried depth of the tunnel is $14-16 \mathrm{~m}$. The tunnel is mainly located in the sandy cobble stratum, whose main components are quartz sandstone and sandstone. The stratum also has a pebble content of approximately $60 \%$, with average and maximum pebble particle sizes of $2-4 \mathrm{~cm}$ and $8-10 \mathrm{~cm}$, respectively. According to laboratory test results, the elastic modulus $E_{t}$ of the sand and gravel formation is $62.4 \mathrm{MPa}$, the internal friction angle $\varphi$ is $30^{\circ}$, and the cohesive force $c$ is $32 \mathrm{kPa}$, which belongs to the ordinary soil layer. The on-site drilling situation is shown in Figure 2.

This project uses a composite earth pressure balance shield machine, which was specially customized by China Railway Shanhe Engineering Equipment Co., Ltd. The diameter of the cutter head of the shield machine is $4.4 \mathrm{~m}$, the length of the shield shell is $7.8 \mathrm{~m}$, and the width of the segment is $1.2 \mathrm{~m}$. In addition, the shield machine is equipped with a profiling knife to meet the construction requirements of the shield machine for tunneling along the curved section. Figure 3 shows the shield machine used in this project. 


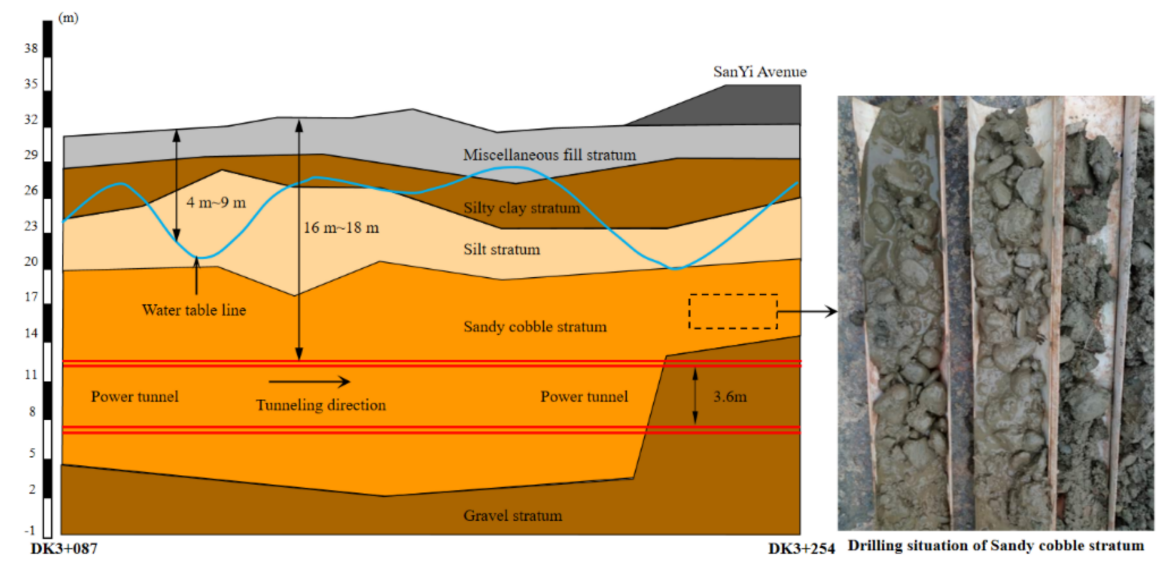

Figure 2. Stratum distribution in the project.

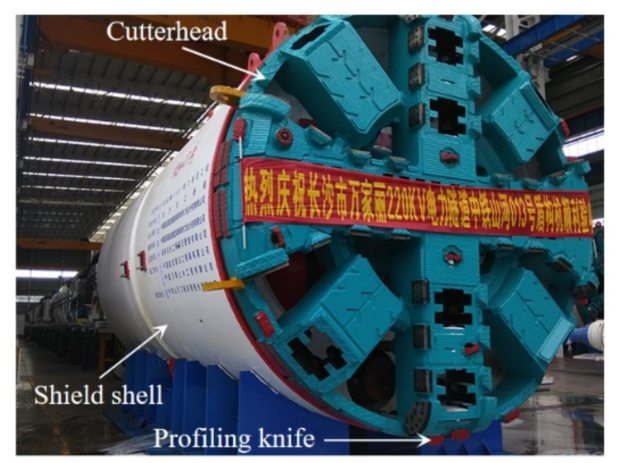

Figure 3. Shield machine used in the project.

The tunneling of the shield along the curved section is performed with two methods [10]. The first method is mainly suitable for soft soil layers. In this method, the shield machine is deflected by adjusting its stroke on both sides of the curved section, causing the shield shell on the inside of the curved section to be compressed by the highly uneven stratum. The significant stroke difference simultaneously causes uneven wear of the cutter head, reducing the life of the shield machine. The second method is mainly suitable for complex formations. First, the profiling knife cuts the inner part of the curved section; then, the jack stroke is slightly adjusted to realize tunneling along the curved section. This method can effectively reduce surrounding stratum compression, thereby reducing the wear and tear of the inner shield shell and the cutter head. However, this method will result in more significant ground loss. The second method was used to realize shield machine tunneling along the curved section with a small radius of curvature during on-site construction according to the stratum and laboratory experiments of the Wanjiali power tunnel project.

\section{Calculation Methods of Pipeline Deformation}

When studying the effect of the shield machine tunneling process on the surrounding environment, the main construction loads, such as the thrust load of the tunnel face, the friction load of the shield shell, and the grouting load, are considered [19]. The thrust load primarily acts on the whole cutter head of the shield machine, the friction load acts on the whole shield shell, and the grouting load generally acts on the $2-4$ ring segments behind the tail of the shield. The distribution of the construction load is illustrated in Figure 4. 


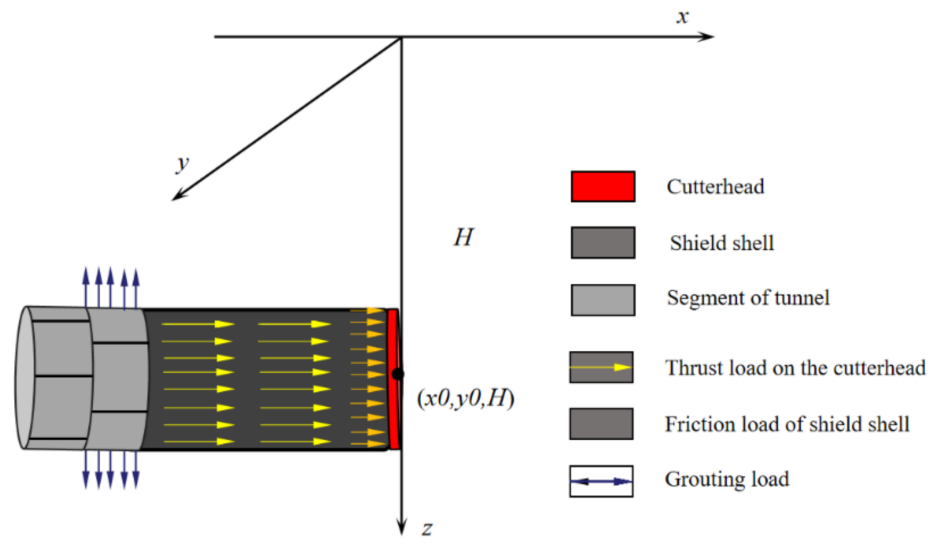

Figure 4. Distribution of construction load.

To facilitate the expressions in the subsequent subsections of this paper, the spatial position relationship between the shield tunnel and the existing pipeline is shown in Figure 5. In this figure, $h$ is the buried depth of the existing pipeline $(\mathrm{m}), b$ is the distance from the cutter head of the shield machine to the intersection point of the tunneling axis and the existing pipeline axis (m), $e$ is the horizontal distance from the calculated point $A$ to the intersection on the pipeline $(\mathrm{m}), \beta$ is the angle between the tunneling axis of the shield machine and the existing pipeline axis $\left(^{\circ}\right), H$ is the depth of the cutter head center point $(\mathrm{m})$, the coordinates of the cutter head center point are $\left(x_{0}, y_{0}, H\right)$, and the coordinates of point $\mathrm{A}$ are $(x, y, h)$.

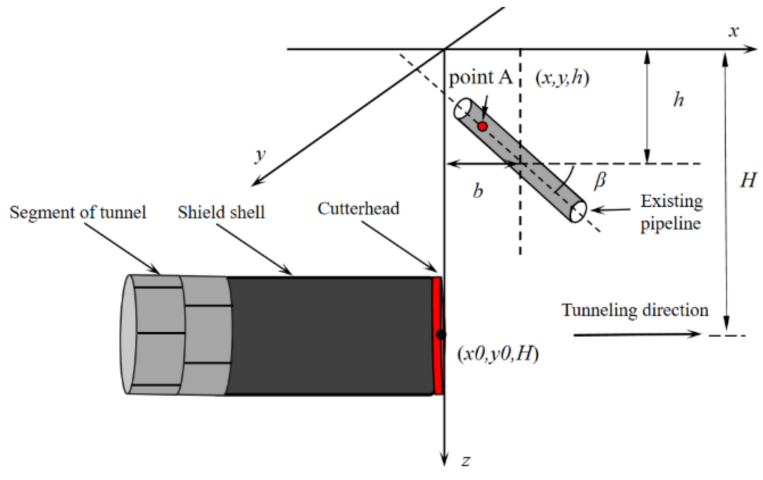

(a) Side view

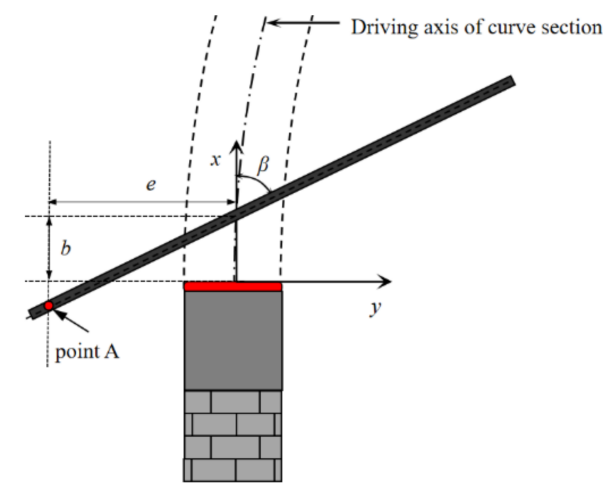

(b) Top view

Figure 5. The spatial relationship between shield tunnels and existing pipelines.

\subsection{Mindlin Solution}

Mindlin [20] took the elastic semi-infinite space body as the research area and derived the settlement calculation formula of any point $(x, y, z)$ in the space caused by the horizontal and vertical loads at a certain point $\left(x_{0}, y_{0}, z_{0}\right)$. Because the calculation model proposed by Mindlin is straightforward, and the formula has relatively few calculation parameters, it is widely used to analyze the disturbance to the surrounding environment caused by tunnel excavation. The calculation diagram is shown in Figure 6. 


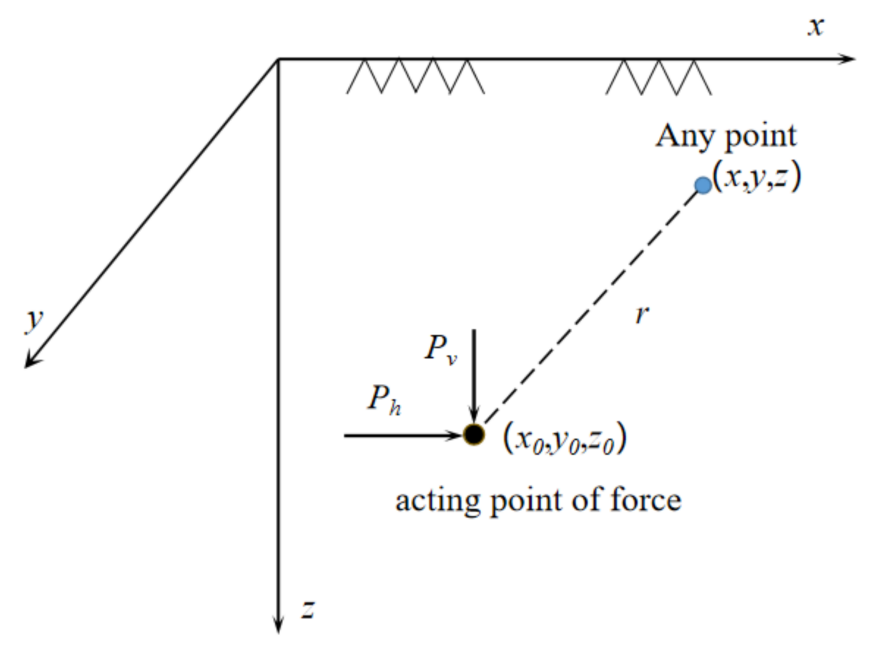

Figure 6. Mindlin calculation diagram.

The vertical deformation $w_{1}$ of one point caused by another point $\left(x_{0}, y_{0}, z_{0}\right)$ under the action of the horizontal load $P_{h}$ is calculated by the formula:

$$
w_{1}=\frac{P_{h}\left(x-x_{0}\right)}{16 \pi G(1-\mu)}\left[\frac{z-z_{0}}{R_{1}^{3}}+\frac{(3-4 \mu)\left(z-z_{0}\right)}{R_{2}^{3}}-\frac{6 z z_{0}\left(z+z_{0}\right)}{R_{2}^{5}}+\frac{4(1-\mu)(1-2 \mu)}{R_{2}\left(R_{2}+z+z_{0}\right)}\right]
$$

The vertical deformation $w_{2}$ of a point caused by another point $\left(x_{0}, y_{0}, z_{0}\right)$ under the action of the vertical load $P_{v}$ is calculated by the formula:

$$
w_{2}=\frac{P_{v}}{16 \pi G(1-\mu)}\left[\frac{3-4 \mu}{R_{1}}+\frac{\left(z-z_{0}\right)^{2}}{R_{1}^{3}}+\frac{8(1-\mu)^{2}-(3-4 \mu)}{R_{2}}+\frac{(3-4 \mu)\left(z+z_{0}\right)^{2}-2 z z_{0}}{R_{2}^{3}}+\frac{6 z z_{0}\left(z+z_{0}\right)^{2}}{R_{2}^{5}}\right]
$$

where $G$ is the shear modulus of the soil, $G=E_{t} /(2(1+\mu))(\mathrm{MPa})$; $E_{t}$ is the elastic modulus of the soil (MPa); $\mu$ is the Poisson's ratio of soil; and $R_{1}=\left[\left(x-x_{0}\right)^{2}+\left(y-y_{0}\right)^{2}+\right.$ $\left.\left(z-z_{0}\right)^{2}\right]^{1 / 2}, R_{2}=\left[\left(x-x_{0}\right)^{2}+\left(y-y_{0}\right)^{2}+\left(z+z_{0}\right)^{2}\right]^{1 / 2}$.

The settlement of the surrounding stratum caused by the construction loads of shield tunneling can be calculated using the Mindlin solution.

\subsubsection{Calculation of Deformation Caused by the Thrust Load}

The thrust load $F_{p}$ is an important indicator to ensure the stable excavation of the shield machine. The thrust load is roughly composed of the static earth pressure load and the additional thrust load required for tunneling. Zhang et al. [21] proposed the following calculation formula of thrust load:

$$
\begin{gathered}
F_{p}=F_{1}+F_{2} \\
F_{1}=\frac{2 E_{t}(1-\eta)}{1-\mu^{2}} V R \\
F_{2}=\pi R^{2}(1-\eta) K_{0} \gamma H+\gamma H
\end{gathered}
$$

where $F_{p}$ is the total thrust acting at the position of the cutter head $(\mathrm{N}) ; F_{1}$ is the propelling force required for the tunneling of the shield machine $(\mathrm{N}) ; F_{2}$ is the force required to balance the earth pressure $(\mathrm{N}) ; E_{t}$ is the elastic modulus of the soil $(\mathrm{MPa}) ; \eta$ is the opening ratio of the cutter head; $V$ is the tunneling speed of the shield machine $(\mathrm{m} / \mathrm{s}) ; R$ is the radius of the cutter head of the shield machine $(\mathrm{m}) ; K_{0}$ is the coefficient of earth pressure at rest, $K_{0}=1$ $-\sin \varphi$; and $\varphi$ is the internal friction angle of the soil $\left(^{\circ}\right)$. 
To calculate the settlement caused by the thrust load, only the action of the additional load $F_{1}$ needs to be considered. However, in this study, $F_{1}$ needs to be converted into a uniform load acting on the cutter head.

To realize the steering of the shield machine, it is necessary for the thrust load to be nonuniformly distributed on both sides of the cutter head [22]. The thrust load on the cutter head outside of the curved section is greater than that inside the curved section, which are $P_{p o}$ and $P_{p i}$, respectively, in this study. The ratio of the two thrust loads is $\mathrm{m}$ (i.e., $\left.P_{p o} / P_{p i}=m, m>1\right)$. According to the relationship between the existing pipeline and the shield tunnel shown in Figure 5, the coordinates $(x, y, h)$ of the calculated point A on the pipeline are transformed into:

$$
\left\{\begin{array}{l}
x=x_{0}+b+e \cos \beta \\
y=y_{0}+e \sin \beta \\
z=h
\end{array}\right.
$$

The coordinates $\left(x_{0}, y_{0}, z_{0}\right)$ of the point on the cutter head need to be transformed into:

$$
\left\{\begin{array}{l}
x_{0}=0 \\
y_{0}=r \cos \theta \\
z_{0}=H-r \sin \theta
\end{array}\right.
$$

The pipeline settlement caused by the thrust load can be obtained by integrating the thrust loads on the inner and outer regions of the cutter head.

$$
\begin{aligned}
w_{q} & =\int_{0}^{R} \int_{-\pi / 2}^{\pi / 2} \frac{P_{p i}(b+e \cos \beta)}{16 \pi G(1-\mu)}\left[\frac{h-H+r \sin \theta}{R_{p 1}^{3}}+\frac{(3-4 \mu)(h-H+r \sin \theta)}{R_{p 2}^{3}}-\frac{6 h(H-r \sin \theta)(h+H-r \sin \theta)}{R_{p 2}^{5}}+\frac{4(1-\mu)(1-2 \mu)}{R_{p 2}\left(R_{p 2}+h+H-r \sin \theta\right)}\right] r d r d \theta \\
& +\int_{0}^{R} \int_{\pi / 2}^{-\pi / 2} \frac{m P_{p i}(b+e \cos \beta)}{16 \pi G(1-\mu)}\left[\frac{h-H+r \sin \theta}{R_{p 1}^{3}}+\frac{(3-4 \mu)(h-H+r \sin \theta)}{R_{p 2}^{3}}-\frac{6 h(H-r \sin \theta)(h+H-r \sin \theta)}{R_{p 2}^{5}}+\frac{4(1-\mu)(1-2 \mu)}{R_{p 2}\left(R_{p 2}+h+H-r \sin \theta\right)}\right] r d r d \theta
\end{aligned}
$$

where $r$ is the distance from the integration point to the center point of the cutter head $(\mathrm{m}), \theta$ is the angle between the integration point and the horizontal line $\left({ }^{\circ}\right)$, and $R_{p 1}=\left[(b+e \cos \beta)^{2}+(e \sin \beta-r \cos \theta)^{2}+(h-H+r \sin \theta)^{2}\right]^{1 / 2} ; R_{p 2}=\left[(b+e \cos \beta)^{2}+(e \sin \beta)^{2}+\right.$ $\left.(h+H-r \sin \theta)^{2}\right]^{1 / 2}$.

The soil layer is unevenly distributed in the actual project, which is very difficult to consider in theoretical calculations. In this study, the soil layer parameters were simplified to a certain extent. Hirai [23] established the theory of the equivalent-layer method, which was later verified by Cao et al. [24] and Zhou et al. [25]. Therefore, this study used the same method to deal with the unevenly distributed soil layer. The conversion formula is as follows.

$$
H_{j e}=\left\{\begin{array}{l}
{\left[\frac{E_{j}\left(1-\mu_{n}{ }^{2}\right)}{E_{n}\left(1-\mu_{j}{ }^{2}\right)}\right]^{1 / 3} H_{j}, E_{j}>E_{n}} \\
\left(\frac{3}{4}+\frac{1}{4}\left[\frac{E_{j}\left(1-\mu_{n}{ }^{2}\right)}{E_{n}\left(1-\mu_{j}{ }^{2}\right)}\right]^{1 / 3}\right) H_{j}, E_{j} \leq E_{n}
\end{array}\right.
$$

where $j$ is the number of soil layers, $1 \leq j \leq n ; E_{j}$ is the elastic modulus of soil layer $j ; \mu_{j}$ is the Poisson's ratio of soil layer $j ; H_{j}$ is the actual thickness of the $j$ th layer; $H_{j e}$ is the equivalent thickness of the $j$ th layer; $E_{n}$ is the elastic modulus for the $n$th layer (base soil layer); and $\mu_{n}$ is the Poisson's ratio for the $n$th layer (base soil layer).

According to Equation (9), the nonuniform soil layer can be transformed into uniform soil layer parameters. The elastic modulus $E_{t}$ of the soil layer where the tunnel is located was assigned to $E_{n}$. Thus, the thickness of the overlying soil layer of the tunnel is equal to $H_{j e}$. Similarly, the relative position of the pipe and the tunnel can be calculated by Equation (9). 


\subsubsection{Calculation of Deformation Caused by Friction Load}

The main factors determining the friction load of the shield shell are the pressure of the surrounding soil, the friction coefficient between the shield shell and the surrounding soil, and the softening coefficient of the soil caused by excavation disturbance. Alonso et al. [26] proposed the calculation formula for the friction load of the shield shell:

$$
f_{1}=\beta_{s} \sigma \tan \alpha
$$

where $\beta_{s}$ denotes the softening coefficient; $\sigma$ is the radial normal stress acting on the shield, $\sigma=\sigma_{v} \sin ^{2} \varphi+\sigma_{h} \cos ^{2} \varphi ; \sigma_{v}$ is the vertical earth pressure, $\sigma_{v}=\gamma H-\gamma R \sin \theta ; \sigma_{h}$ is the horizontal earth pressure (kPa); $\gamma$ is the heaviness of the soil $\left(\mathrm{kN} / \mathrm{m}^{3}\right) ; \sigma_{h}=K \sigma_{v} ; K=1-$ $\sin \varphi ; \varphi$ is the soil friction angle $\left({ }^{\circ}\right)$; and $\alpha$ is the angle of shin friction $\left(^{\circ}\right)$.

The magnitudes of friction loads are different on both sides of the shield shell because of the different earth pressures. Previous studies and engineering cases have shown that the friction load of the shield shell inside the curved section is considerably greater than that of the shield shell outside the curved section. Therefore, overcutting can only reduce the nonuniform coefficient value, whereas it cannot eliminate the nonuniform distribution of the friction load resistance of the shield shell [27]. This paper assumes that the friction loads inside and outside of the curved section are $P_{f i}$ and $P_{f_{0}}$, respectively, and their ratio is $n$ (i.e., $\left.P_{f_{0}} / P_{f i}=n, n<1\right)$. The coordinates $\left(x_{0}, y_{0}, z_{0}\right)$ of the point on the shield shell need to be transformed into:

$$
\left\{\begin{array}{l}
x_{0}=-s \\
y_{0}=R \cos \theta \\
z_{0}=H-R \sin \theta
\end{array}\right.
$$

Substituting friction loads of the shield shell into Equation (1) and integrating the range of the inner and outer shield shell, respectively, the pipeline settlement caused by the friction load of the shield shell is obtained as follows.

$$
\begin{aligned}
w_{q} & =\int_{0}^{L} \int_{-\pi / 2}^{\pi / 2} \frac{P_{f i}(b+e \cos \beta+s)}{16 \pi G(1-\mu)}\left[\frac{h-H+R \sin \theta}{R_{f 1}^{3}}+\frac{(3-4 \mu)(h-H+R \sin \theta)}{R_{f 2}^{3}}-\frac{6 h(H-R \sin \theta)(h+H-R \sin \theta)}{R_{f 2}^{5}}+\frac{4(1-\mu)(1-2 \mu)}{R_{f 2}\left(R_{f 2}+h+H-R \sin \theta\right)}\right] R d s d \theta \\
& +L \int_{0}^{R} \int_{\pi / 2}^{-\pi / 2} \frac{n P_{f i}(b+e \cos \beta+s)}{16 \pi G(1-\mu)}\left[\frac{h-H+R \sin \theta}{R_{f 1}^{3}}+\frac{(3-4 \mu)(h-H+R \sin \theta)}{R_{f 2}^{3}}-\frac{6 h(H-R \sin \theta)(h+H-R \sin \theta)}{R_{f 2}^{5}}+\frac{4(1-\mu)(1-2 \mu)}{R_{f 2}\left(R_{f 2}+h+H-R \sin \theta\right)}\right] R d s d \theta
\end{aligned}
$$

where $s$ is the horizontal distance from the integration point to the cutter head $(\mathrm{m}), L$ is the length of the shield shell of the shield machine $(\mathrm{m})$, and $R_{f 1}=\left[(b+e \cos \beta+s)^{2}\right.$ $\left.+(e \sin \beta-R \sin \theta)^{2}+(h-H+R \sin \theta)^{2}\right]^{1 / 2} ; R_{f 2}=\left[(b+e \cos \beta+s)^{2}+(e \sin \beta-R \sin \theta)^{2}+\right.$ $\left.(h+H-R \sin \theta)^{2}\right]^{1 / 2}$.

\subsubsection{Calculation of Deformation Caused by Grouting Load}

The shield tail synchronous grouting can fill the gap caused by excavation, and the additional grouting load can compress the stratum and reduce the continuous settlement of the ground. Nematollahi and Dias [28] proposed the following calculation formula of grouting load:

$$
P_{j} \approx 1.2 \cdot \sigma_{v}
$$

The coordinates $\left(x_{0}, y_{0}, z_{0}\right)$ of the point on the grouting area need to be transformed into:

$$
\left\{\begin{array}{l}
x_{0}=-L-a \\
y_{0}=R \cos \theta \\
z_{0}=H-R \sin \theta
\end{array}\right.
$$

The grouting load is decomposed into vertical load $P_{j v}$ and horizontal load $P_{j h}$, which are substituted into Equations (1) and (2), respectively. The deformation caused by the grouting load can be obtained as follows: 


$$
\begin{aligned}
w_{q} & =\int_{0}^{3 l 2 \pi} \int_{0} \frac{P_{j v}(b+e \cos \beta+a+L)}{16 \pi G(1-\mu)}\left[\frac{h-H+R \sin \theta}{R_{j 1}^{3}}+\frac{(3-4 \mu)(h-H+R \sin \theta)}{R_{j 2}^{3}}-\frac{6 h(H-R \sin \theta)(h+H-R \sin \theta)}{R_{j 2}^{5}}+\frac{4(1-\mu)(1-2 \mu)}{R_{j 2}\left(R_{j 2}+h+H-R \sin \theta\right)}\right] R d a d \theta \\
& +\int_{0}^{3 l 2 \pi} \int_{0} \frac{P_{j h}}{16 \pi G(1-\mu)}\left[\frac{3-4 \mu}{R_{j 1}}+\frac{(h-H+R \sin \theta)^{2}}{R_{j 1}^{3}}+\frac{(3-4 \mu)(h+H-R \sin \theta)^{2}-2 h(H-R \sin \theta)}{R^{3}{ }_{j 2}}+\frac{6 h(H-R \sin \theta)(h+H-R \sin \theta)^{2}}{R^{5}{ }_{j 2}}\right] R d a d \theta
\end{aligned}
$$

where $a$ is the horizontal distance from the integration point to the shield tail $(\mathrm{m}), l$ is the length of the segment $(\mathrm{m})$, and $R_{j 1}=\left[(b+e \cos \beta+L+a)^{2}+(e \sin \beta-R \sin \theta)^{2}+\right.$ $\left.(h-H+R \sin \theta)^{2}\right]^{1 / 2} ; R_{j 2}=\left[(b+e \cos \beta+L+a)^{2}+(e \sin \beta-R \sin \theta)^{2}+(h+H-R \sin \theta)^{2}\right]^{1 / 2}$.

\subsection{Calculation of Deformation Caused by Ground Loss}

The ground loss caused by the shield machine along the curved section is composed of two parts. The first part is located at the tail of the shield shell and is called the integrative gap of the shield tail (IGST). It is caused by the construction process and the inverted cone structure of the shield machine and occurs during tunneling along straight and curved sections [29]. The second part is the ground loss caused by overcutting the inside of the curved section and is called the overcutting gap (OG). The ground loss during shield machine tunneling along the curved section is summarized in Figure $7 . R_{0}$ is the turning radius of tunneling.

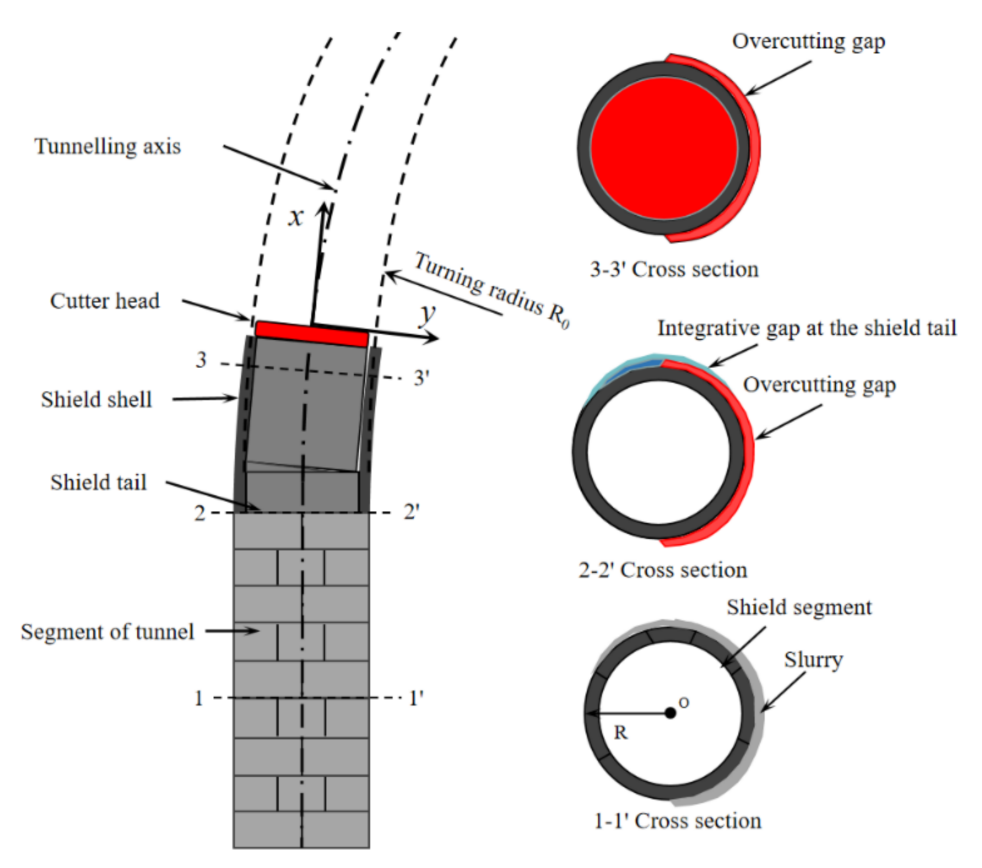

Figure 7. Ground loss model in curved section.

\subsubsection{Calculation of Deformation Caused by the IGST}

Lee et al. [30] proposed a calculation model for the IGST during shield tunneling, as shown in Figure 8.

The calculation formula for the IGST is as follows:

$$
I G S T=G_{p}+u_{3 D}^{*}+\omega
$$

where $G_{p}$ is the physical gap at the shield tail when grouting is not considered. $G_{p}$ is equal to the gap between the tunnel segment and the soil after the tunnel segment emerges from the shield tail, i.e., $G_{p}=2 \Delta+\delta^{\prime}$, where $\Delta$ denotes the shield thickness, and $\delta^{\prime}$ denotes the clearance required for tunnel segment erection. When the grouting effect is considered, $G_{p}$ should be appropriately reduced. $u_{3 D}^{*}$ is the equivalent $3 \mathrm{D}$ elastoplastic displacement at the excavation face; generally, when the soil at the tunnel face is in a state of mechanical 
equilibrium, $u_{3 D}^{*}=0$, and $\omega$ is the clearance parameter, with yawing excavation as the main factor. When the elevation and depression angles of the shield machine are not considered, $\omega=0$.

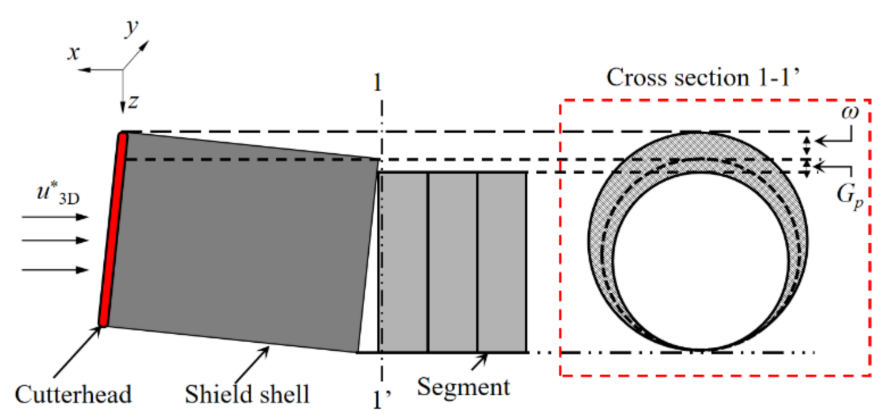

Figure 8. Model of IGST.

Loganathan [31] derived the calculation formula of the surrounding soil settlement $w_{I G A P}$ caused by the IGST.

$$
w_{I G A P}=2(1-\mu)\left(R g-g^{2} / 4\right) \times \frac{H}{\left(x-x_{0}+L\right)^{2}+(z-H)^{2}} \times \exp \left[-\frac{1.38\left(x-x_{0}\right)^{2}}{(z-H)^{2}}\right] \times\left(1-\frac{\left(y-y_{0}\right)}{\sqrt{\left(x-x_{0}+L\right)^{2}+\left(y-y_{0}\right)^{2}+(z-H)^{2}}}\right)
$$

where $(x, y, z)$ are the coordinates of the calculated point, $\left(x_{0}, y_{0}, H\right)$ are the coordinates of the center point of the cutter head, and $g$ is the formation loss parameter $(\mathrm{m})$.

\subsubsection{Calculation of Deformation Caused by OG}

Huynh et al. [32] indicated that the entire process generates overcutting from the extension of the over-digging cutter to the retraction. At the same time, there is no synchronous grouting system in the shield shell, implying that the OG is not effectively filled until the shield tail passes through. Thus, the OG exists in the entire area between the cutter head and the shield tail. In actual construction, the OG is usually unevenly distributed because of soil conditions and construction factors. For ease of calculation, the OG is regarded as uniform in this paper.

According to the above analysis, the ground loss model between the cutter head and the shield tail is established as shown in Figure 9.

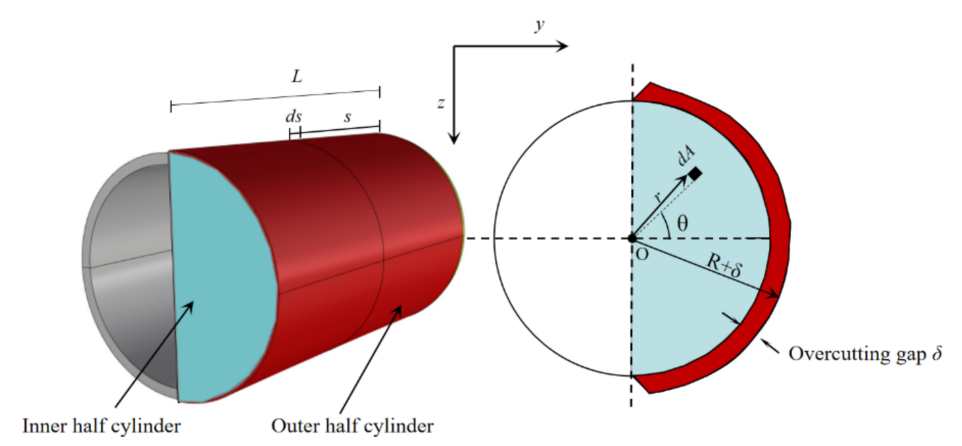

Figure 9. Diagram of OG calculation.

Festa et al. [33] proposed the calculation formula of the crosscutting amount $\delta$ :

$$
\delta=\frac{\sqrt{\left(2 R_{0}+2 R\right)^{2}+L^{2}}-\left(2 R_{0}+2 R\right)}{2}
$$

where $R_{0}$ is the turning radius (m), and $\delta$ is the thickness of the OG $(\mathrm{m})$.

Sagaseta [34] deduced the formula for the displacement field change caused by the unit volume void in the elastic semi-infinite space body. The settlement change amount of 
the calculated point is the settlement $S_{0}$ caused by the shear stress and the settlement $S_{z 1}$ and $S_{z 2}$ caused by the volume change. They are calculated as follows:

$$
\begin{gathered}
S_{0}=-\frac{3}{4 \pi^{2}} \lim _{b \rightarrow \infty c \rightarrow \infty} \lim _{y_{1}-b x_{1}-c}^{y_{1}+b x_{1}+c}\left[\frac{z}{R_{s}^{3}}+\frac{1-2 u}{R_{s}\left(R_{s}+z\right)}\right] \times\left\{\frac{z_{1}\left(u-x_{1}\right)(x-u)}{\left[\left(u-x_{1}\right)^{2}+\left(t-y_{1}\right)^{2}+z_{1}\right]^{2 / 2}}-\frac{z_{1}\left(t-x_{1}\right)(y-t)}{\left[\left(u-x_{1}\right)^{2}+\left(t-y_{1}\right)^{2}+z_{1}{ }^{2}\right]^{5 / 2}}\right\} d u d t \\
S_{\mathrm{z} 1}=-\frac{1}{4 \pi} \frac{\left(z-z_{1}\right)}{r_{1}^{3}} \\
S_{\mathrm{z} 2}=\frac{1}{4 \pi} \frac{\left(z+z_{1}\right)}{r_{2}{ }^{3}}
\end{gathered}
$$

where $\left(x_{1}, y_{1}, z_{1}\right)$ are the coordinates of void points; $b$ and $c$ are the integral ranges in the $X$ and $Y$ directions, respectively; $u$ and $t$ are the virtual integral variables; $R_{S}=\left[(x-u)^{2}\right.$ $\left.+(y-t)^{2}+z^{2}\right]^{1 / 2} ; r_{1}=\left[\left(x-x_{1}\right)^{2}+\left(y-y_{1}\right)^{2}+\left(z-z_{1}\right)^{2}\right]^{1 / 2} ; r_{2}=\left[\left(x-x_{1}\right)^{2}+\left(y-y_{1}\right)^{2}+\right.$ $\left.\left(z+z_{1}\right)^{2}\right]^{1 / 2}$.

When calculating the surface settlement caused by the OG, the OG can be regarded as the difference between two half-cylinders. Among them, the area of the infinitesimal body in the integration region is $d A=r d \theta$, as shown in Figure 9.

The gap point coordinates $\left(x_{1}, y_{1}, z_{1}\right)$ are transformed into:

$$
\left\{\begin{array}{l}
x_{1}=x_{0}-s \\
y_{1}=y_{0}+r \cos \theta \\
z_{1}=H-r \sin \theta
\end{array}\right.
$$

Combining Figure 9 and Equations (18), (19) and (22), the calculation formula for the ground settlement induced by the $O G$ is:

$$
w_{O G}=\int_{-\pi / 2}^{\pi / 2} \int_{R}^{R+\delta} \int_{0}^{L}\left(S_{0}+S_{z 1}+S_{z 2}\right) d \theta d r d s
$$

The calculation formula for the deformation of the existing pipeline caused by the tunneling of the shield machine along the curved section can be obtained.

$$
w_{\mathrm{g}}=w_{p}+w_{f}+w_{q}+w_{I G A P}+w_{O G}
$$

\subsection{Calculation of Pipeline Deformation Consider Pipe-Soil Coupling}

Equation (24) is used to calculate the settlement of the surrounding stratum caused by shield machine tunneling along the curved section. However, it is necessary to consider the coupling between the pipe and the soil to obtain the pipeline deformation [35]. In this study, the existing pipeline is regarded as a continuous Euler-Bernoulli beam placed on a foundation beam, and the soil layer is regarded as a Pasternak two-parameter foundation beam [36]. The calculation model for the coupling effect of the existing pipeline and the soil layer is shown in Figure 10. 


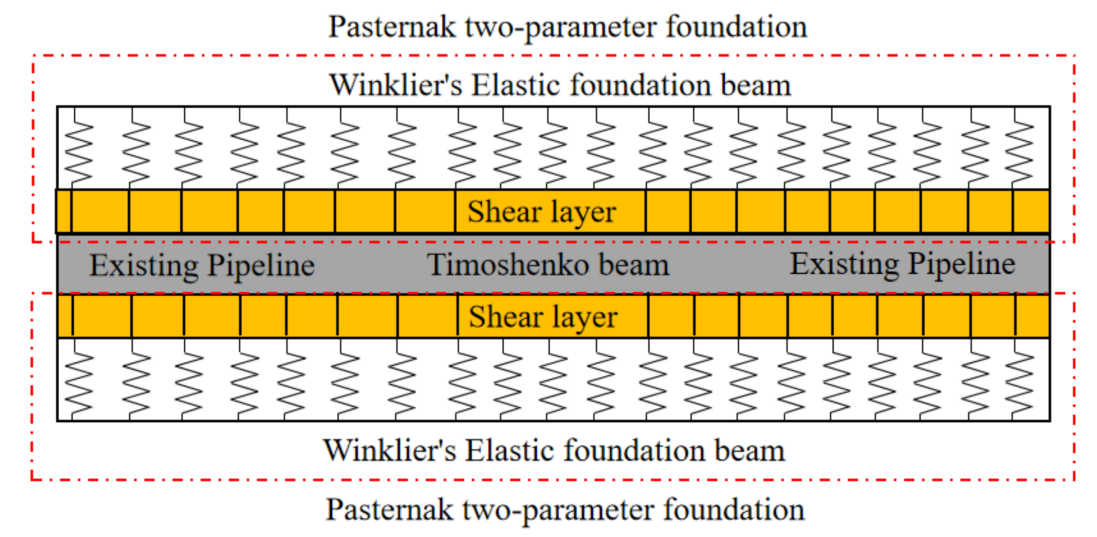

Figure 10. Pipeline soil layer coupling model.

The Pasternak two-parameter foundation is composed of the Winkler elastic foundation beam and the soil shear layer $[37,38]$. The deflection differential equation of Pasternak two-parameter foundation can be expressed as follows [39]:

$$
q(z)=k w_{g}-G_{C} \frac{\partial^{2} w_{G}(z)}{\partial y^{2}}+\frac{E I}{d} \frac{\partial^{4} w_{G}(z)}{\partial y^{4}}
$$

where $q(z)$ is the additional load on the existing pipeline, and $q(z)=k w_{g} ; w_{g}$ is the settlement deformation of the soil at the corresponding pipeline position and is calculated using Equation (24); $d$ and EI are the width and bending stiffness of the existing pipeline, respectively. The accuracy of EI will affect the accuracy of the calculation results, although the value of pipeline $E I$ is still not clear at this stage. In this study, according to the calculation method of tunnel bending rigidity $E I$, the reduction coefficient method calculates the bending rigidity $E I$ of the pipeline. $k$ is the elastic modulus of the Winkler elastic foundation beam [40]; $G_{c}$ is the shear modulus of the shear layer [41].

$$
\begin{gathered}
k=\frac{1.3 E_{t}}{d\left(1-\mu^{2}\right)} \sqrt[12]{\frac{E_{t} d^{4}}{E I}} \\
G_{c}=\frac{E_{t} h_{t}}{6(1+\mu)}
\end{gathered}
$$

Equation (25) is a high-order differential equation, which is challenging to solve using conventional calculation methods. The finite difference method is one of the crucial methods used to solve high-order differential equations. The pipeline was discretized into $2 N+5$ units with a length of $t$ (including $2 N+1$ units in the calculation range and two virtual units on both sides of the calculation range). The existing pipeline after discretization is shown in Figure 11.

High-order differential equations can be transformed using the finite difference method as follows:

$$
\left\{\begin{array}{l}
\frac{\partial^{4} w_{N}(z)}{\partial y^{4}}=\frac{6 w_{N}(z)-4\left(w_{N+1}(z)+w_{N-1}(z)\right)+\left(w_{N+2}(z)+w_{N-2}(z)\right)}{t^{4}} \\
\frac{\partial^{2} w_{N}(z)}{\partial y^{2}}=\frac{w_{N+1}(z)-2 w_{N}(z)+w_{N-1}(z)}{t^{2}}
\end{array}\right.
$$

The points on the boundary of the calculation range $B$ (points 0 and $N$ ) are regarded as unaffected by the shield tunnel excavation, and the bending moment $M_{0(N)}$ and shear force $Q_{0(N)}$ of the corresponding points are equal to 0 , which can be obtained as follows:

$$
\left\{\begin{array}{l}
M_{0}=M_{N}=-E I \frac{d^{2} w_{0}(z)}{d y^{2}}=-E I \frac{d^{2} w_{2 N}(z)}{d y^{2}}=0 \\
Q_{0}=Q_{N}=-E I \frac{d^{3} w_{0}(z)}{d y^{3}}=-E I \frac{d^{3} w_{2 N}(z)}{d y^{3}}=0
\end{array}\right.
$$


Combining the boundary conditions and the finite difference equation, the displacement expressions of the four virtual nodes outside the calculation range $B$ can be obtained as:

$$
\left\{\begin{array}{l}
w_{-1}=4 w_{0}-4 w_{1}+w_{2} \\
w_{-2}=2 w_{-1}-w_{0} \\
w_{2 N+1}=2 w_{2 N}-w_{2 N-1} \\
w_{2 N+2}=4 w_{2 N}-4 w_{2 N-1}+w_{2 N-2}
\end{array}\right.
$$

According to Equations (28) and (30), the iterative operation can determine the displacement relationship of all units after discretization. Substituting Equation (30) into the deflection differential Equation (25), $2 N+1$ equations can be obtained, and the corresponding equations can be converted to matrix equations:

$[q(z)]_{(2 N+1)(2 N+1)}=\left\{[k]_{(2 N+1)(2 N+1)}-[G]_{(2 N+1)(2 N+1)}+[K]_{(2 N+1)(2 N+1)}\right\}\left[w_{\mathrm{G}}(z)\right]_{(2 N+1)(2 N+1)}$

where $[q(z)]_{2 N+1}$ is the matrix of the additional load acting on the units, $[k]_{2 N+1}$ is the coefficient matrix of the soil foundation bed, $[G]_{2 N+1}$ is the shear layer stiffness matrix, $[K]_{2 N+1}$ is the pipe stiffness matrix, and $\left[w_{G}(z)\right]_{2 N+1}$ is the deformation matrix of the discrete units.

$$
\begin{aligned}
& {[k]=k\left[\begin{array}{llll}
1 & & & 0 \\
& \ddots & & \\
& & \ddots & \\
0 & & & 1
\end{array}\right]_{(2 N+1) \times(2 N+1)}} \\
& {\left[G_{c}\right]=\frac{G_{c}}{t^{2}}\left[\begin{array}{cccccc}
-2 & 2 & & & & \\
1 & -2 & 1 & & & \\
& \ddots & \ddots & \ddots & & \\
& & \ddots & \ddots & \ddots & \\
& & & 1 & -2 & 1 \\
& & & & 2 & -2
\end{array}\right]_{(2 N+1) \times(2 N+1)}}
\end{aligned}
$$

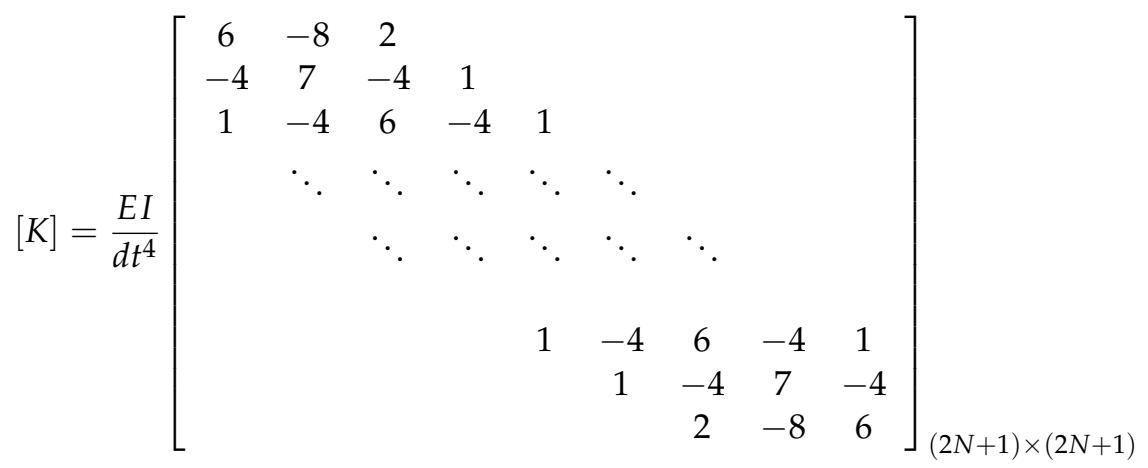

Substituting the stiffness matrix Equations (32)-(34) and each calculation parameter into the deflection differential Equation (31), the deformation data of the existing pipeline considering the coupling effect of the existing pipeline and the soil layer can be obtained. 


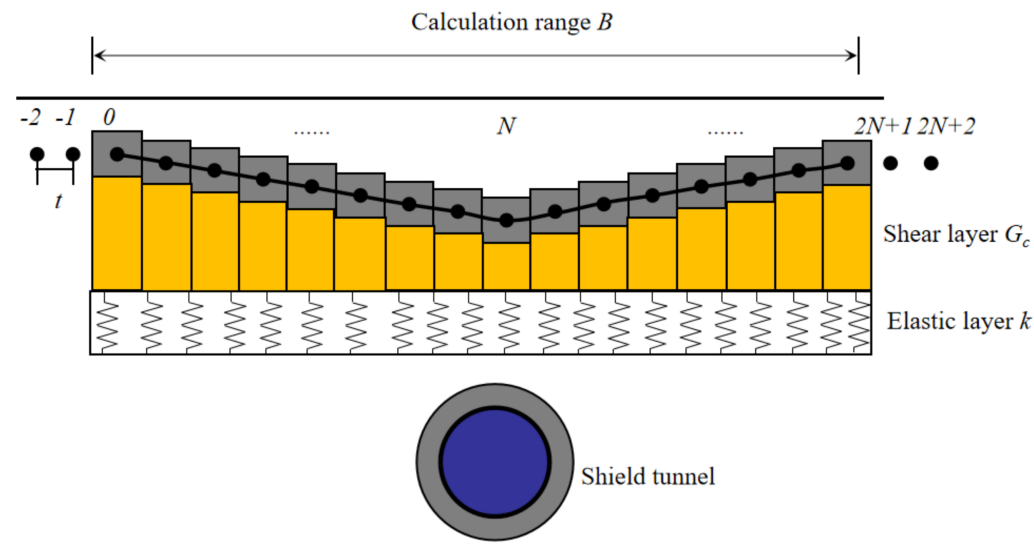

Figure 11. Discrete pipeline model.

According to the above calculation formula, the theoretical calculation can be carried out according to the steps shown in Figure 12.

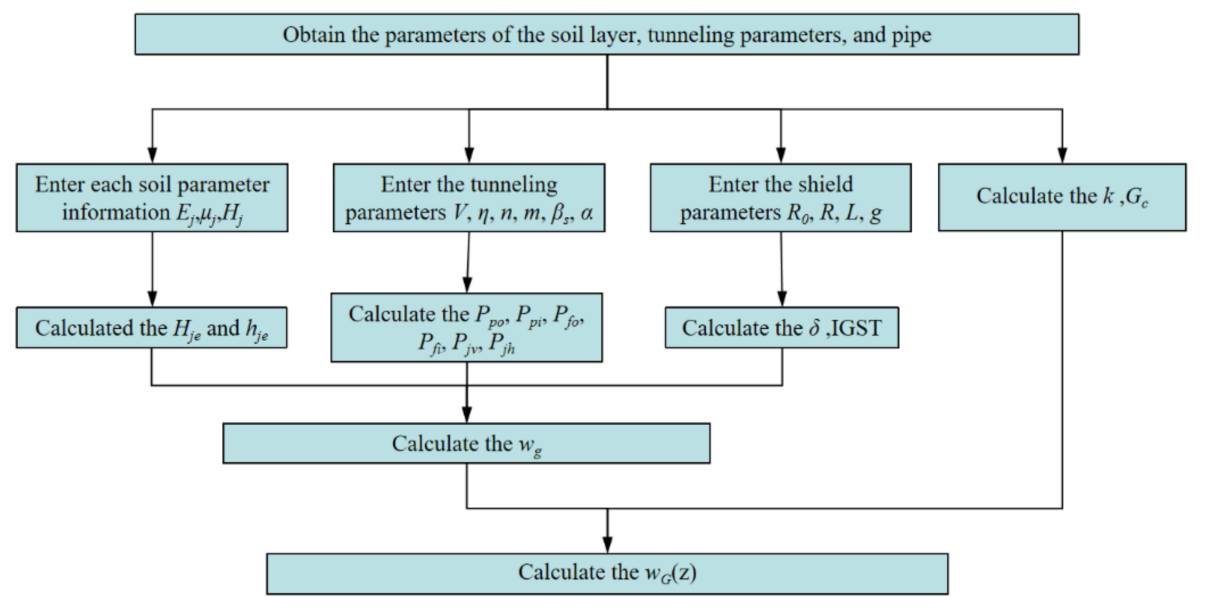

Figure 12. Theoretical calculation steps.

\section{Numerical Calculation Model}

\subsection{Finite Difference Model}

The numerical calculation model takes the curved section of shield tunnel DK3 +560 $\sim \mathrm{DK} 3+254$ as the background. The model considers the most unfavorable conditions during construction, with the buried depths of the tunnel, the water table, and the existing pipeline being $15 \mathrm{~m}, 3 \mathrm{~m}$, and $4 \mathrm{~m}$, respectively. Nematollahi and Dias [42] pointed out that the boundary effect on the accuracy of the calculation results can be ignored when the distance from the model boundary to the tunnel is more significant than four times the tunnel diameter. To determine the central area of the existing upper pipeline that is disturbed by shield tunneling, the boundary size of the model is increased. The final size of the numerical calculation model is determined to be $100 \mathrm{~m} \times 100 \mathrm{~m} \times 33 \mathrm{~m}$, and the model is shown in Figure 13. The following are the boundary conditions: no horizontal displacement along all vertical mesh boundaries, no vertical and horizontal displacements along the bottom of the mesh, and free movement along the top boundary. 

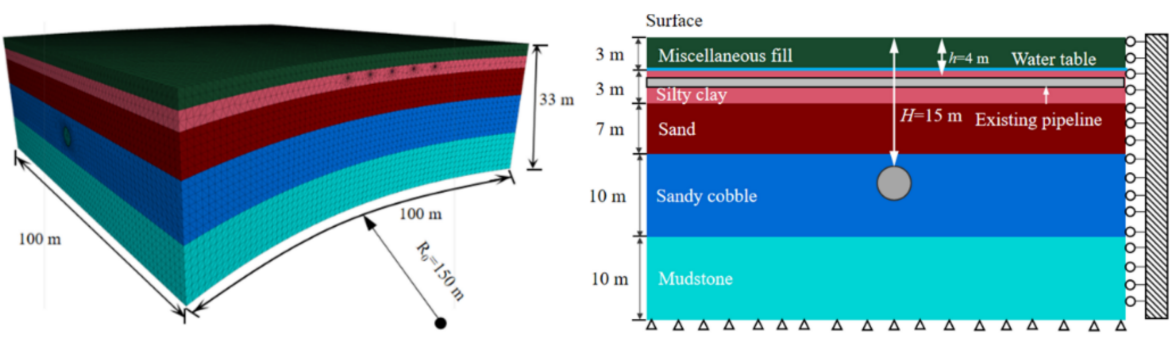

Figure 13. Finite difference model.

The shield machine model of the curved section, which is different from the model of the straight section, includes the cutter head, shield shell, grouting process of the shield tail, OG, and IGST. In simulating the tunneling of the shield machine, a nonuniformly distributed load needs to be applied on the cutter head and shield shell on both sides of the curved section. For this purpose, the cutter head and shield shell are each divided into two areas. According to Equation (16), the height of the IGST is $0.018 \mathrm{~m}$, and the distribution range of the IGST must be determined according to the actual construction situation and construction technology; this distribution range is set as $0.1 \mathrm{~m}$ in this study [43]. According to Equation (18), the void height of the OG, which is attached to the shield shell on the inner side of the curve, is calculated to be $0.044 \mathrm{~mm}$. The calculation model of the shield machine is shown in Figure 14.

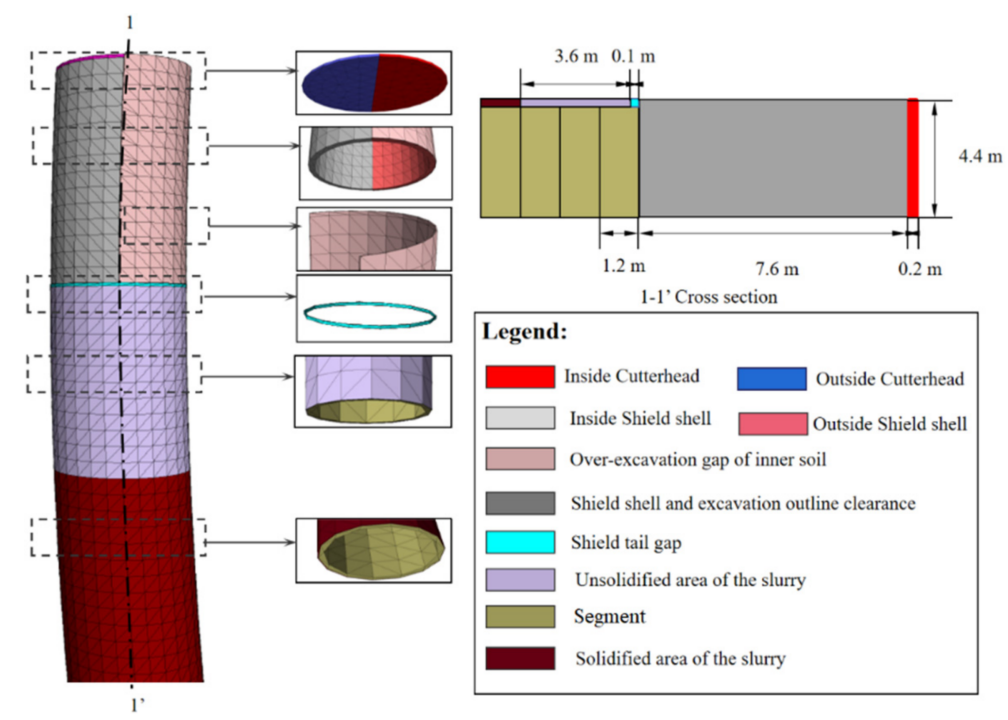

Figure 14. Shield machine calculation model.

\subsection{Loads in the Numerical Calculation Model}

According to the monitoring of the thrust of the hydraulic jack on-site, the thrust of the hydraulic jack on the outside of the cutter head is around 1.7 times that of the hydraulic jack on the inside during tunneling along the curved section $(m=1.7)$. The opening ratio $\eta$ of the cutter head is $60 \%$, and the tunneling speed is approximately $0.5 \mathrm{~m} / \mathrm{h}$. According to Equation (4), the additional thrust of the tunnel face is $1.95 \mathrm{MN}$ at the inside of the cutter head, and the additional thrust load at the outside of the cutter head is $3.32 \mathrm{MN}$. The thrust force is converted into uniform loads $P_{p o}=2.18 \times 10^{5} \mathrm{~Pa}$ and $P_{p i}=1.29 \times 10^{5} \mathrm{~Pa}$ applied on the outside and inside of the cutter head, respectively.

Potyondy [43] demonstrated that the force on the contact surface between the shield shell and the sandy gravel formation is relatively small. Therefore, in this paper, the friction angle of the shield shell surface is taken as $10^{\circ}$, and the softening coefficient is taken as 0.9 . Therefore, the frictional load $P_{f}$ on the surface is $17.9 \times 10^{3} \mathrm{~Pa}$. The authors of [27] pointed out that when the shield machine tunnels along the curved section, the ratio coefficient 
of the friction loads of the inside and outside of the shield shell is generally 1.2-3.2; the ratio is smaller in the case of over-excavation. In this paper, the ratio coefficient is 1.5 when considering over-excavation measures $(n=1.5)$. Then, the frictional resistances when the force is applied on the outside and inside of the shield shell are $P_{f_{0}}=48.9 \times 10^{3} \mathrm{~Pa}$ and $P_{f i}=73.4 \times 10^{3} \mathrm{~Pa}$, respectively.

According to Equation (10), the grouting pressure $P_{j}$ is $3.24 \times 10^{5} \mathrm{~Pa}$. Therefore, the calculated construction load is applied to the corresponding unit of the shield machine, as shown in Figure 15.

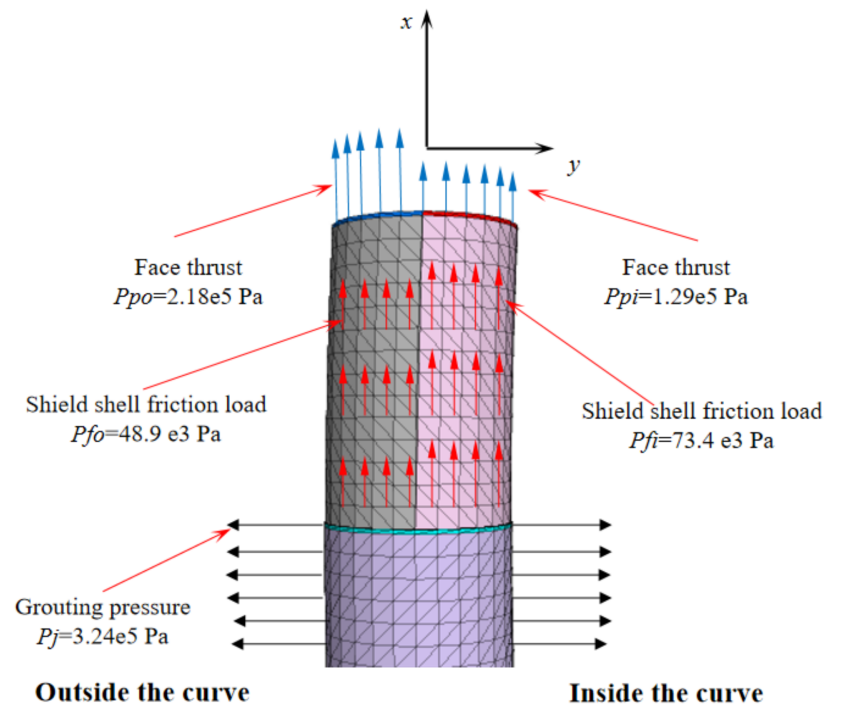

Figure 15. Load application situation in FDM model.

\subsection{Material Properties}

In the FDM, the constitutive model of the soil can be the soft soil model, soft soil creep model, hardening soil with small strain model, and Mohr-Coulomb model (MC) [11]. These four models only have minor differences in the analysis of the disturbance in shortterm shield tunneling. Nevertheless, the parameters of the MC model are more accessible and suitable for guiding site construction $[44,45]$. Therefore, this study assumes that the soil layer is a homogeneous and isotropic elastoplastic body and conforms to the MC failure criterion. The soil layer parameters were selected according to the geological survey report and laboratory tests, as shown in Table 1.

Table 1. Soil material parameters.

\begin{tabular}{cccccc}
\hline Soil Materials & $\gamma\left(\mathbf{k N} / \mathbf{m}^{3}\right)$ & $\left.\boldsymbol{\varphi} \mathbf{(}^{\circ}\right)$ & $c(\mathbf{k P a})$ & $\left.\boldsymbol{E}_{\boldsymbol{t}} \mathbf{( M P a}\right)$ & $\boldsymbol{\mu}$ \\
\hline Miscellaneous fill & 17.2 & 5 & 5 & 1.5 & 0.33 \\
Silty clay & 17.8 & 8 & 15 & 4.2 & 0.32 \\
Sand & 18.5 & 15 & 2 & 45.0 & 0.28 \\
Sand cobble & 18.8 & 30 & 32 & 62.4 & 0.25 \\
Mudstone & 19.2 & 35 & 50 & 147.8 & 0.23 \\
\hline
\end{tabular}

The cutter head and shield shell of the shield machine were simulated using elastic bodies. Owing to the support in the shield shell, its rigidity is the same as that of the cutter head, and the material strength parameters are approximately equal to the strength parameters of steel. Shield tail grouting materials can be divided into two states: solidified and unsolidified. According to field experiments and related research [46], the grouting slurry is in an unsolidified state on the first day, while it solidifies after seven days. The strength of the solidified slurry is approximately four times that of the unsolidified slurry, and the strength of the slurry is unchanged after seven days. Therefore, in the present 
model, the slurry within the width of the three-ring segment behind the shield tail is regarded as being in the unsolidified state, and that outside the three-ring segment is regarded as being in the solidified state.

The segments are also assumed to be elastic bodies. Usually, the elastic modulus $E$ and Poisson's ratio of C50 grade concrete are $36 \mathrm{GPa}$ and 0.24 , respectively. The bending moment transmission ratio $\xi$ is used to calculate the reduction effect of the joint on the strength of the segment, as follows:

$$
E_{c}=(1-\xi) E
$$

where $E_{c}$ is the elastic modulus of the segment after considering the joint, and $\xi$ is the bending moment transmission ratio. The Japanese Civil Engineering Society recommends a value range of $\xi=0.7-0.9$. In this study, $\xi$ is taken as 0.9 , which is consistent with the literature [47].

Compared with that of the shield tunnel, the connection strength of the existing pipeline is lower. Therefore, in the calculation model, it is assumed that the material of the existing pipeline is $\mathrm{C} 20$ concrete, with a bending moment transmission ratio $\xi$ of 0.95 . All material parameters are listed in Table 2.

Table 2. Shield machine parameters.

\begin{tabular}{cccc}
\hline Shield Machine Material & $\gamma\left(\mathbf{k N} / \mathbf{m}^{\mathbf{3}}\right)$ & $\boldsymbol{E} \mathbf{( G P a )}$ & $\mu$ \\
\hline Cutter head & 70 & 200 & 0.20 \\
Shield shell & 70 & 200 & 0.20 \\
Segment (C50) & 25.2 & 3.6 & 0.24 \\
Unsolidified area of the slurry & & 0.0083 & 0.36 \\
Solidification area of the slurry & & 0.045 & 0.30 \\
Existing pipeline (C20) & 20.3 & 2.3 & 0.26 \\
\hline
\end{tabular}

\subsection{Numerical Simulation Process}

The numerical simulation model considers many factors, and constructing a dynamic tunneling model is highly complicated. It is proposed that the tunneling process can be simulated by constructing multiple static models. In this study, 13 numerical calculation models were constructed to compare the applicability of the theoretical formulas. The positional relationship between the pipeline and the shield tunnel in the model is shown in Table 3. When $b$ is a negative value, it means that the pipeline is located behind the cutter head.

Table 3. Distribution of pipelines in the numerical calculation model.

\begin{tabular}{ccccc}
\hline Model Number & $\boldsymbol{b}(\mathbf{m})$ & $\left.\boldsymbol{\beta} \mathbf{(}^{\circ}\right)$ & $\boldsymbol{h}(\mathbf{m})$ & $\boldsymbol{e}(\mathbf{m})$ \\
\hline 1 & -10 & 90 & 4 & \pm 30 \\
2 & 0 & 90 & 4 & \pm 30 \\
3 & 10 & 90 & 4 & \pm 30 \\
4 & -10 & 30 & 4 & \pm 30 \\
5 & -10 & 45 & 4 & \pm 30 \\
6 & -10 & 60 & 4 & \pm 30 \\
7 & 0 & 30 & 4 & \pm 30 \\
8 & 0 & 45 & 4 & \pm 30 \\
9 & 0 & 60 & 4 & \pm 30 \\
10 & -20 & 90 & 4 & \pm 30 \\
11 & -30 & 90 & 4 & \pm 30 \\
12 & 20 & 90 & 4 & \pm 30 \\
13 & 30 & 90 & & \\
\hline
\end{tabular}

The simulation process of each model is divided into three stages: 
Step 1: Each part of the model, according to the soil layer of the corresponding depth, was assigned material properties, and then the initial stress field and initial displacement field were calculated. Finally, the initial displacement field was reset to zero, and the initial stress field was retained.

Step 2: The soil in the pipeline was removed, and the corresponding material was assigned to the pipeline. After the pipeline excavation was calculated, the displacement field and stress field were calculated, the displacement field was returned to zero, and the stress field was retained. The purpose of this step is to correspond to the theoretical calculation. The influence of previous construction on the new excavation step was not considered.

Step 3: The soil in the shield shell area was removed. Simultaneously, the cutter head, the shield shell, the segment, and the grouting area were assigned to corresponding material parameters, the unit of the IGST and OG was assigned to the null unit. Finally, according to the situation in Figure 15, the corresponding load in the corresponding unit was applied and run to obtain the calculation result.

\section{Analysis of Calculation Results}

\subsection{Analysis of Surface Settlement}

The cloud map of surface settlement when the shield machine is tunneling to $x=0 \mathrm{~m}$ is shown in Figure 16.

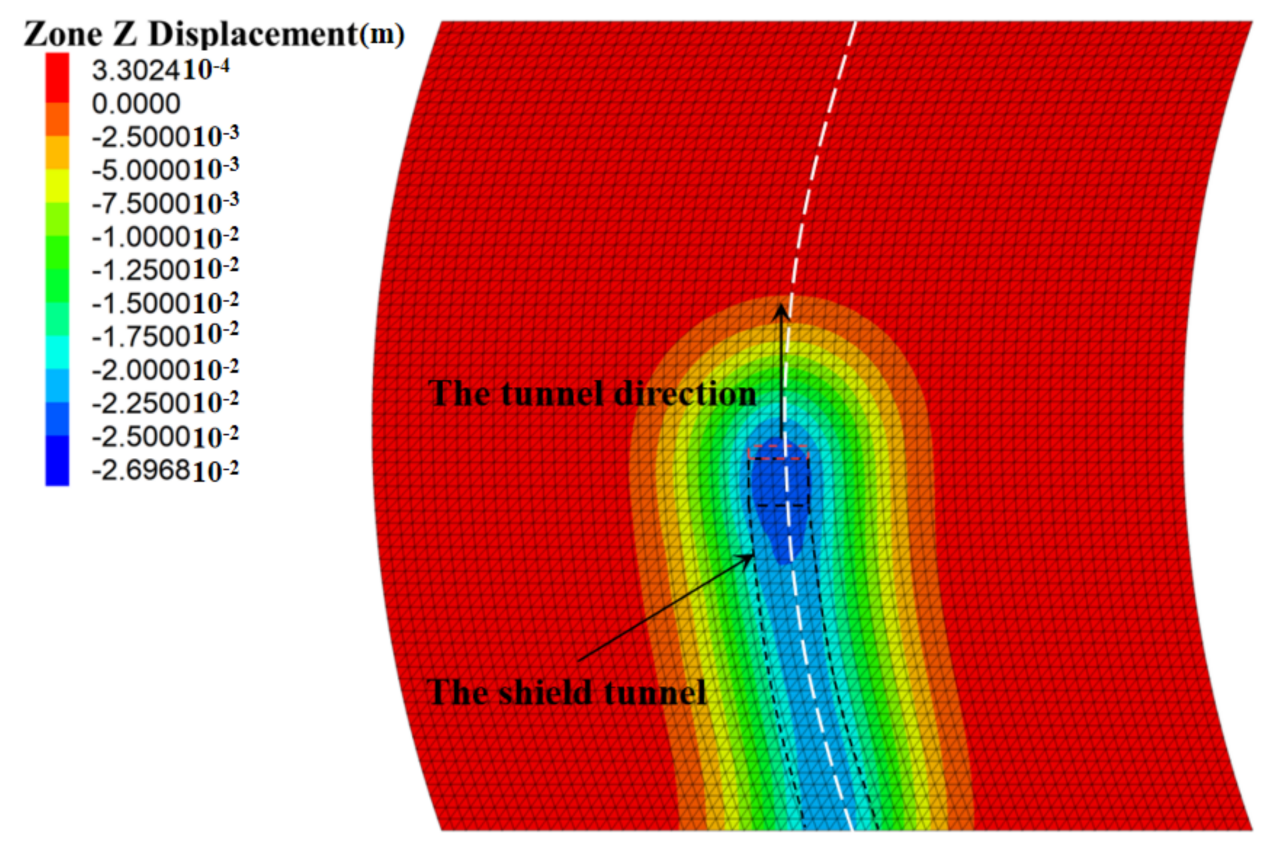

Figure 16. Cloud map of surface subsidence.

The surface settlement values at the cross-sectional positions of $x=-10 \mathrm{~m}, 0 \mathrm{~m}$, and $10 \mathrm{~m}$ were extracted, and the field monitoring data and the prediction results obtained using the theoretical formula are compared in Figure 17. 


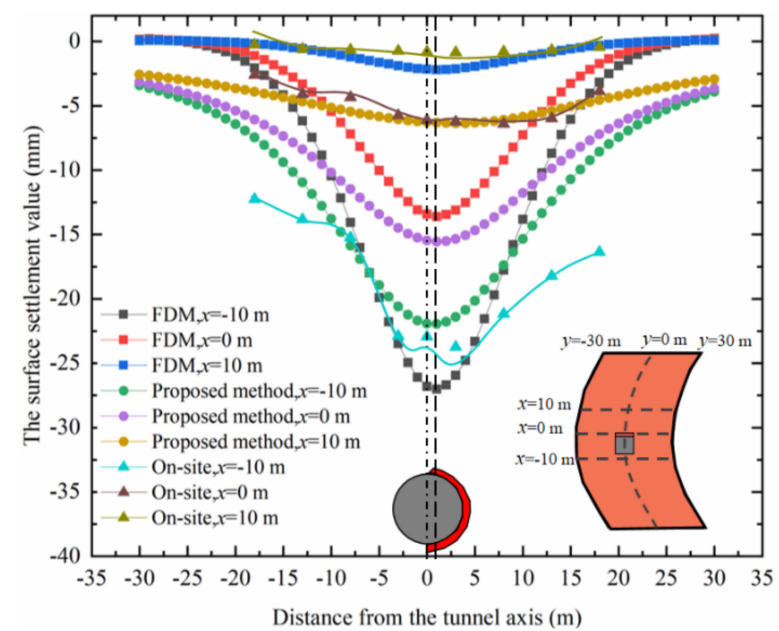

Figure 17. Comparison of surface settlement curves.

The following results are observed:

(1) Numerical simulation results, theoretical prediction results, and on-site monitoring data indicate that the maximum surface subsidence is $27 \mathrm{~mm}, 22 \mathrm{~mm}$, and $24 \mathrm{~mm}$, respectively, and the error range of the calculation results is within $10 \%$. Thus, the rationality of the proposed prediction formula and FDM is verified.

(2) When the shield machine is tunneling along the curved section, the ground settlement is distributed asymmetrically in a " $\mathrm{V}$ " shape, which is different from the ground settlement law in the case of tunneling along the straight section. The theoretical prediction results indicate that the maximum ground settlement position deviates from the tunnel axis, which is located inside the curved section approximately 1 $\mathrm{m}$ away from the tunnel axis. This law derived from theoretical calculations is consistent with that calculated by the FDM. The field monitoring data show that the surface settlement near the inside of the curved section is greater than that outside of the curved section; however, the maximum settlement position deviates to a greater degree.

(3) Comparison of the data of the three monitoring sections indicates that in the monitoring section closer to the tail of the shield machine, the greater the surface settlement value, the more comprehensive the range of the surface settlement trough.

The surface settlement data at the $y=0 \mathrm{~m}$ section were extracted, and the surface settlement curve distribution is shown in Figure 18.

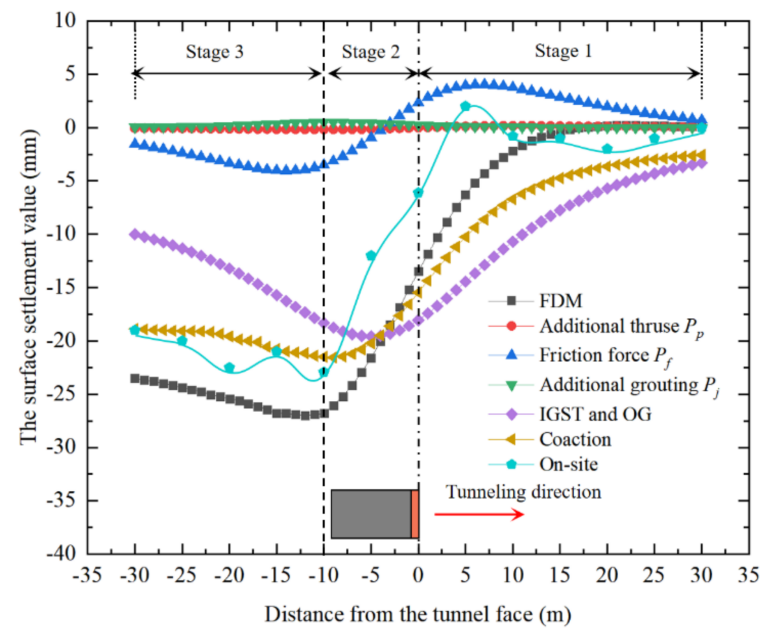

Figure 18. Comparison of surface settlement curves at $y=0 \mathrm{~m}$. 
(1) The surface settlement curve along the direction of excavation is " $\mathrm{S}$ " shaped and can be divided into three stages: slow development stage (stage 1), intensive development stage (stage 2), and stable development stage (stage 3). This law of vertical distribution on the surface is consistent with that previously reported [48].

(2) Among the shield machine construction factors discussed in this paper, the leading causes of the ground settlement are the friction load of the shield shell and ground loss. The additional thrust load and the grouting pressure have little effect on the ground settlement.

(3) The maximum settlement of the ground surface is located behind the shield tail. The maximum settlements obtained by numerical simulation, theoretical calculation, and on-site monitoring are $26 \mathrm{~mm}, 22 \mathrm{~mm}$, and $24 \mathrm{~mm}$, respectively, at positions $12 \mathrm{~m}, 10$ $\mathrm{m}$, and $10 \mathrm{~m}$, respectively, behind the cutter head. Once again, the above data prove the accuracy of the numerical calculation model and the proposed formula.

\subsection{Pipeline Deformation Analysis}

The lateral deformation data of the pipelines in models 1-9 were extracted and are shown in Figure 19.

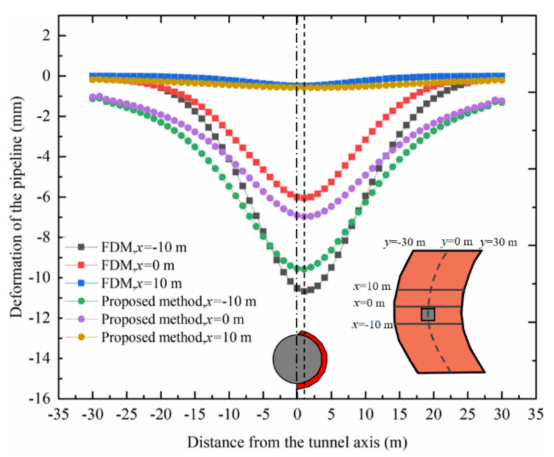

(a) $x=-10 \mathrm{~m}, x=0 \mathrm{~m}, x=10 \mathrm{~m}\left(\beta=0^{\circ}\right)$.

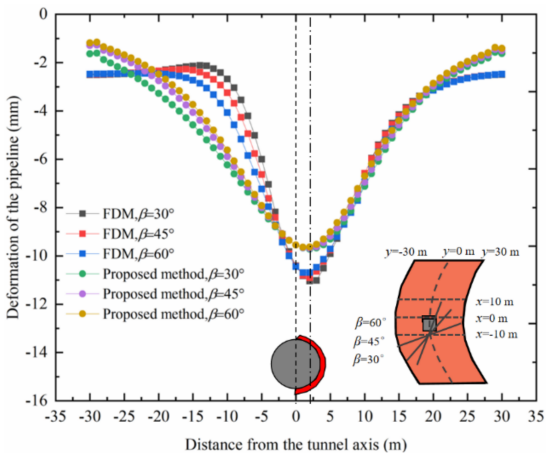

(b) $\beta=30^{\circ}, \beta=45^{\circ}, \beta=60^{\circ}(x=-10 \mathrm{~m})$

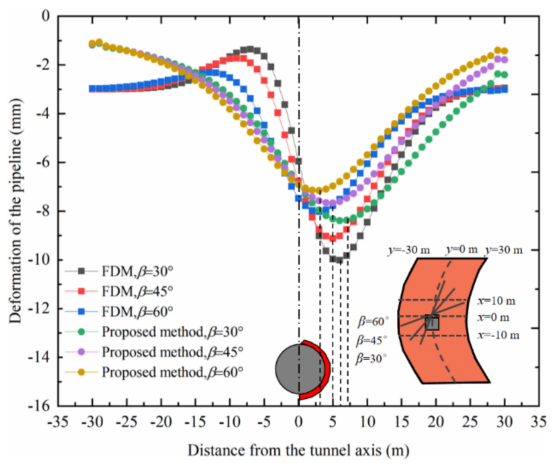

(c) $\beta=30^{\circ}, \beta=45^{\circ}, \beta=60^{\circ}(x=-0 \mathrm{~m})$

Figure 19. Comparison of lateral settlement of pipelines. 
(1) Figure 19a shows that when the pipeline axis is parallel to the tunnel axis, the deformation of the pipeline is asymmetrically distributed in a " $\mathrm{V}$ " shape, and the maximum deformation position deviates from the tunnel axis. This is different from the law of surface settlement caused by tunneling along the straight section. The maximum deformation values of the pipeline according to the numerical simulation and theoretical calculation are approximately $11 \mathrm{~mm}$ and $9.5 \mathrm{~mm}$, respectively.

(2) Figure $19 \mathrm{~b}$ shows that when the pipeline axis and the excavation axis intersect at $x=-10 \mathrm{~m}$, the change in the included angle $\beta$ has little effect on the maximum deformation of the pipeline. Moreover, the maximum deformation position of the pipeline deviates from the tunnel axis by approximately $2 \mathrm{~m}$.

(3) Figure 19c shows that when the pipeline axis and the tunneling axis intersect at $x=0 \mathrm{~m}$, the included angle $\beta$ has a significant effect on the maximum deformation of the pipeline. With continuously increasing $\beta$, the maximum deformation value of the pipeline gradually decreases, and the maximum settlement position is closer to the tunnel axis.

The maximum deformation of the pipeline in model 1, model 2, model 3, model 10, model 11, model 12, and model 13 was extracted, and the maximum deformation of the existing pipeline that was caused by the tunneling process of the shield machine is shown in Figure 20.

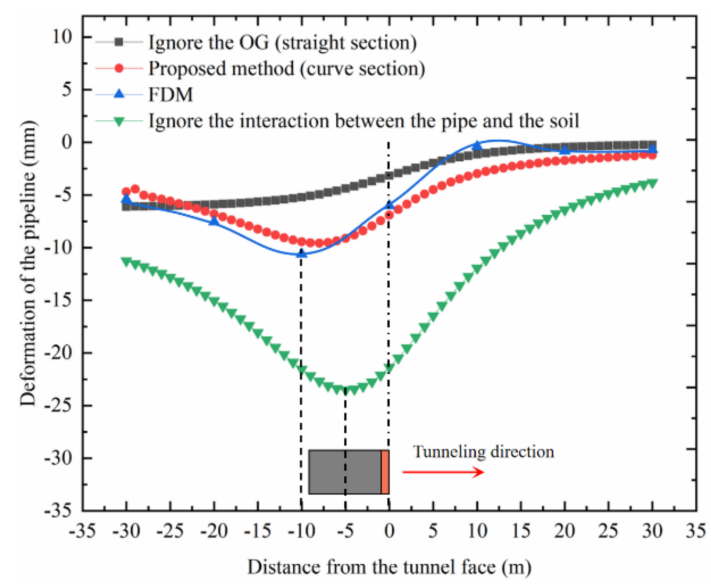

Figure 20. Maximum deformation curve of pipeline.

The calculation result without considering the coupling between the pipe and the soil is much greater than the numerical simulation calculation result, and the calculation result is less than the numerical simulation result without considering the OG. The error between the theoretical prediction results and the FDM result is small, which proves that it is reasonable to consider the existing pipes as Euler-Bernoulli beams acting on the Pasternak two-parameter foundation.

\section{Conclusions}

In this study, a theoretical prediction formula for the deformation of an existing pipeline caused by shield machine tunneling along a curved section was derived. In addition, the FDM for the Wanjiali power tunnel was constructed. Then, the deformation of the ground surface and existing pipelines was analyzed. The following conclusions can be drawn from the research results:

(1) The results of the proposed theoretical prediction, FDM calculation, and field monitoring data are consistent, with a small deviation; this verifies the rationality of the proposed formula.

(2) When the shield machine is tunneling along the curved section, the horizontal deformation curves of the ground surface and the existing pipeline are asymmetrically distributed in a "V" shape, and the maximum settlement position appears on the 
inside of the curved section, which is around $0.5 R$ away from the tunnel axis. By contrast, the longitudinal deformation curves of the ground surface and the pipeline are distributed in an " $\mathrm{S}$ " shape, and the maximum settlement position is behind the shield tail. The shield shell friction and ground loss are the main factors affecting the surrounding stratum during the tunneling process.

(3) When the pipeline axis and the tunneling axis intersect behind the cutter head, the included angle $\beta$ between the pipe axis and the excavation axis does not affect the maximum deformation and position of the deformation. However, when both axes intersect before the cutter head, the maximum deformation of the pipe increases, and the position of maximum deformation gradually becomes closer to the tunnel axis with increasing $\beta$.

(4) When analyzing the deformation of the existing pipeline caused by tunneling of the shield machine along the curved section, it is necessary to consider the ground loss caused by the OG and the coupling effect between the soil layer and the pipeline. In addition, the existing pipeline deformation and surface settlement caused by shield machine tunneling along the curved section is much larger than those caused by tunneling along the straight section. Therefore, special attention should be paid to the disturbance of the surrounding environment caused by shield machine tunneling along curved sections.

Author Contributions: Methodology, software, data processing, writing-original draft, H.D.; conceptualization, methodology, supervision, project administration, H.F.; validation, formal analysis, writing-review and editing, Y.S.; validation, formal analysis, writing-review and editing, Z.H.; language checking, Q.H. All authors have read and agreed to the published version of the manuscript.

Funding: This study was financially supported by the National Natural Science Foundation of China (Grant Nos. 51578550, 51538009, and 51978668).

Institutional Review Board Statement: Not applicable.

Informed Consent Statement: Not applicable.

Data Availability Statement: Not applicable.

Acknowledgments: The authors thank the Advanced Research Center, Central South University, for providing the experimental conditions. The authors also express special thanks to the editors and anonymous reviewers for their constructive comments. Finally, the authors would like to acknowledge the support provided by the Changsha City Public Works Construction Center. The authors would like to thank all the reviewers who participated in the review and MJ Editing for its linguistic assistance during the preparation of this manuscript.

Conflicts of Interest: The authors declare that they have no known competing financial interests or personal relationships that could have appeared to influence the work reported in this paper.

\section{References}

1. Huang, M.; Zhou, X.; Yu, J.; Leung, C.; Tan, J.Q.W. Estimating the effects of tunnelling on existing jointed pipelines based on Winkler model. Tunn. Undergr. Space Technol. 2019, 86, 89-99. [CrossRef]

2. Zhang, J.; Xie, R.; Zhang, H. Mechanical response analysis of the buried pipeline due to adjacent foundation pit excavation. Tunn. Undergr. Space Technol. 2018, 78, 135-145. [CrossRef]

3. Ma, S.; Li, M.; Jin, J.; Bai, K. The influence of shallow buried double-line parallel rectangular pipe jacking construction on ground settlement deformation. Alex. Eng. J. 2021, 60, 1911-1916. [CrossRef]

4. Fang, Q.; Zhang, D.; Li, Q.; Wong, L.N.Y. Effects of twin tunnels construction beneath existing shield-driven twin tunnels. Tunn. Undergr. Space Technol. 2015, 45, 128-137. [CrossRef]

5. Zhang, D.-M.; Huang, Z.-K.; Li, Z.-L.; Zong, X. Analytical solution for the response of an existing tunnel to a new tunnel excavation underneath. Comput. Geotech. 2019, 108, 197-211. [CrossRef]

6. Miliziano, S.; de Lillis, A. Predicted and observed settlements induced by the mechanized tunnel excavation of metro line $\mathrm{C}$ near S. Giovanni station in Rome. Tunn. Undergr. Space Technol. 2019, 86, 236-246. [CrossRef]

7. Cheng, W.-C.; Song, Z.-P.; Tian, W.; Wang, Z.-F. Shield tunnel uplift and deformation characterisation: A case study from Zhengzhou metro. Tunn. Undergr. Space Technol. 2018, 79, 83-95. [CrossRef] 
8. Lin, X.-T.; Chen, R.-P.; Wu, H.-N.; Cheng, H. Deformation behaviors of existing tunnels caused by shield tunneling undercrossing with oblique angle. Tunn. Undergr. Space Technol. 2019, 89, 78-90. [CrossRef]

9. Yu, C.; Han, C.; Xie, R.; Wang, L. Mechanical behavior analysis of buried pipeline under stratum settlement caused by underground mining. Int. J. Press. Vessel. Pip. 2020, 188, 188. [CrossRef]

10. Cheng, H.; Chen, R.; Wu, H.; Meng, F.; Yi, Y. General solutions for the longitudinal deformation of shield tunnels with multiple discontinuities in strata. Tunn. Undergr. Space Technol. 2021, 107, 103652. [CrossRef]

11. Ni, P.; Mangalathu, S. Fragility analysis of gray iron pipelines subjected to tunneling induced ground settlement. Tunn. Undergr. Space Technol. 2018, 76, 133-144. [CrossRef]

12. Zhang, Z.; Zhang, M. Mechanical effects of tunneling on adjacent pipelines based on Galerkin solution and layered transfer matrix solution. Soils Found. 2013, 53, 557-568. [CrossRef]

13. Hou, Y.; Fang, Q.; Zhang, D.; Wong, L.N.Y. Excavation failure due to pipeline damage during shallow tunnelling in soft ground. Tunn. Undergr. Space Technol. 2015, 46, 76-84. [CrossRef]

14. Zhang, C.; Yu, J.; Huang, M. Effects of tunnelling on existing pipelines in layered soils. Comput. Geotech. 2012, 43, 12-25. [CrossRef]

15. Zhang, M.; Li, S.; Li, P. Numerical analysis of ground displacement and segmental stress and influence of yaw excavation loadings for a curved shield tunnel. Comput. Geotech. 2020, 118, 103325. [CrossRef]

16. Deng, H.-S.; Fu, H.-L.; Yue, S.; Huang, Z.; Zhao, Y.-Y. Ground loss model for analyzing shield tunneling-induced surface settlement along curve sections. Tunn. Undergr. Space Technol. 2021, 119, 104250. [CrossRef]

17. Wu, D.; Xu, K.; Guo, P.; Lei, G.; Cheng, K.; Gong, X. Ground Deformation Characteristics Induced by Mechanized Shield Twin Tunnelling along Curved Alignments. Adv. Civ. Eng. 2021, 2021,1-17. [CrossRef]

18. Xie, X.; Tang, G. Effects of curved shield tunnelling adjacent to existing power tunnel. Eur. J. Environ. Civ. Eng. 2017, 22, s164-s178. [CrossRef]

19. Liang, R.; Xia, T.; Hong, Y.; Yu, F. Effects of above-crossing tunnelling on the existing shield tunnels. Tunn. Undergr. Space Technol. 2016, 58, 159-176. [CrossRef]

20. Mindlin, R.D. Force at a Point in the Interior of a Semi-Infinite Solid. Physics 1936, 7, 195-202. [CrossRef]

21. Zhang, Q.; Hou, Z.; Huang, G.; Cai, Z.; Kang, Y. Mechanical characterization of the load distribution on the cutterhead-ground interface of shield tunneling machines. Tunn. Undergr. Space Technol. 2015, 47, 106-113. [CrossRef]

22. Alsahly, A.; Stascheit, J.; Meschke, G. Advanced finite element modeling of excavation and advancement processes in mechanized tunneling. Adv. Eng. Softw. 2016, 100, 198-214. [CrossRef]

23. Hirai, H. Settlements and stresses of multi-layered grounds and improved grounds by equivalent elastic method. Int. J. Numer. Anal. Methods Géoméch. 2008, 32, 523-557. [CrossRef]

24. Cao, L.; Zhang, D.; Fang, Q. Semi-analytical prediction for tunnelling-induced ground movements in multi-layered clayey soils. Tunn. Undergr. Space Technol. 2020, 102, 103446. [CrossRef]

25. Zhou, Z.; Chen, Y.; Liu, Z.; Miao, L. Theoretical prediction model for deformations caused by construction of new tunnels undercrossing existing tunnels based on the equivalent layered method. Comput. Geotech. 2020, 123, 103565. [CrossRef]

26. Alonso, E.E.; Josa, A.; Ledesma, A. Negative skin friction on piles: A simplified analysis and prediction procedure. Géotechnique 1984, 34, 341-357. [CrossRef]

27. Li, S.; Li, P.; Zhang, M. Analysis of additional stress for a curved shield tunnel. Tunn. Undergr. Space Technol. 2021, 107, 103675. [CrossRef]

28. Nematollahi, M.; Dias, D. Three-dimensional numerical simulation of pile-twin tunnels interaction-Case of the Shiraz subway line. Tunn. Undergr. Space Technol. 2019, 86, 75-88. [CrossRef]

29. Yin, M.; Jiang, H.; Jiang, Y.; Sun, Z.; Wu, Q. Effect of the excavation clearance of an under-crossing shield tunnel on existing shield tunnels. Tunn. Undergr. Space Technol. 2018, 78, 245-258. [CrossRef]

30. Lee, K.M.; Rowe, R.K.; Lo, K.Y. Subsidence owing to tunnelling. I. Estimating the gap parameter. Can. Geotech. J. 1992, 29, 929-940. [CrossRef]

31. Loganathan, N.; Poulos, H.G. Analytical Prediction for Tunneling-Induced Ground Movements in Clays. J. Geotech. Geoenvironm. Eng. 1998, 124, 846-856. [CrossRef]

32. Huynh, T.; Chen, J.; Sugimoto, M. Analysis on shield operational parameters to steer articulated shield. Jpn. Geotech. Soc. Spéc. Publ. 2016, 2, 1497-1500. [CrossRef]

33. Festa, D.; Broere, W.; Bosch, J. Kinematic behaviour of a Tunnel Boring Machine in soft soil: Theory and observations. Tunn. Undergr. Space Technol. 2015, 49, 208-217. [CrossRef]

34. Sagaseta, C. Analysis of undraind soil deformation due to ground loss. Géotechnique 1987, 37, 301-320. [CrossRef]

35. Mohanty, R. An unconditionally stable finite difference formula for a linear second order one space dimensional hyperbolic equation with variable coefficients. Appl. Math. Comput. 2005, 165, 229-236. [CrossRef]

36. Liang, R.; Xia, T.; Huang, M.; Lin, C. Simplified analytical method for evaluating the effects of adjacent excavation on shield tunnel considering the shearing effect. Comput. Geotech. 2017, 81, 167-187. [CrossRef]

37. Liang, L.; Xu, C.; Zhu, B.; Deng, J. Theoretical method for an elastic infinite beam resting on a deformable foundation with a local subsidence. Comput. Geotech. 2020, 127, 103740. [CrossRef] 
38. Liu, Z.; Xue, J.; Ye, J.; Qian, J. A simplified two-stage method to estimate the settlement and bending moment of upper tunnel considering the interaction of undercrossing twin tunnels. Transp. Geotech. 2021, 29, 100558. [CrossRef]

39. El Kahi, E.; Deck, O.; Khouri, M.; Mehdizadeh, R.; Rahme, P. Influence of geometrical uncertainties of analytical modelling on the evaluation of building deflections induced by ground movements. Eur. J. Environ. Civ. Eng. 2020, 1-15. [CrossRef]

40. Attewell, P.B.; Yeates, J.; Selby, A.R. Soil Movements Induced by Tunnelling and their Effects on Pipelines and Structures; Methuen Inc.: New York, NY, USA, 1986.

41. Tanahashi, H. Formulas for an Infinitely Long Bernoulli-Euler Beam on the Pasternak Model. Soils Found. 2004, 44, 109-118. [CrossRef]

42. Nematollahi, M.; Dias, D. Interaction between an underground parking and twin tunnels-Case of the Shiraz subway line. Tunn. Undergr. Space Technol. 2020, 95, 103150. [CrossRef]

43. Potyondy, J.G. Skin Friction between Various Soils and Construction Materials. Géotechnique 1961, 11, 339-353. [CrossRef]

44. Dai, X.; Cai, J.; Diao, Y.; Huo, H.; Xu, G. Influence of tunnelling on the deformation of the overlying excavation bracing system and analysis of countermeasures. Comput. Geotech. 2021, 134, 104089. [CrossRef]

45. Lai, H.; Zheng, H.; Chen, R.; Kang, Z.; Liu, Y. Settlement behaviors of existing tunnel caused by obliquely under-crossing shield tunneling in close proximity with small intersection angle. Tunn. Undergr. Space Technol. 2020, 97, 103258. [CrossRef]

46. Oggeri, C.; Oreste, P.; Spagnoli, G. The influence of the two-component grout on the behaviour of a segmental lining in tunnelling. Tunn. Undergr. Space Technol. 2021, 109, 103750. [CrossRef]

47. Li, X.; Zhou, X.; Hong, B.; Zhu, H. Experimental and analytical study on longitudinal bending behavior of shield tunnel subjected to longitudinal axial forces. Tunn. Undergr. Space Technol. 2019, 86, 128-137. [CrossRef]

48. Fang, Y.; Chen, Z.; Tao, L.; Cui, J.; Yan, Q. Model tests on longitudinal surface settlement caused by shield tunnelling in sandy soil. Sustain. Cities Soc. 2019, 47, 101504. [CrossRef] 